\title{
Bmi-1 Regulates Snail Expression and Promotes Metastasis Ability in Head and Neck Squamous Cancer-Derived ALDH1 Positive Cells
}

\author{
Cheng-Chia Yu, ${ }^{1,2}$ Wen-Liang Lo, ${ }^{3}$ Yi-Wei Chen, ${ }^{4}$ Pin-I Huang, ${ }^{4,5}$ Han-Shui Hsu, ${ }^{6}$ Ling-Ming \\ Tseng, ${ }^{6}$ Shih-Chieh Hung, ${ }^{4,5}$ Shou-Yen Kao, ${ }^{3}$ Charn-Jung Chang, ${ }^{7}$ and Shih Hwa Chiou ${ }^{4,5}$
}

\author{
${ }^{1}$ Institute of Oral Biology and Biomaterial Science, Chung-Shan Medical University, Taichung 40201, Taiwan \\ ${ }^{2}$ Department of Dentistry, Chung Shan Medical University Hospital, Taichung 40201, Taiwan \\ ${ }^{3}$ Division of Oral and Maxillofacial Surgery, Department of Stomatology, Taipei Veterans General Hospital, Taipei 11217, Taiwan \\ ${ }^{4}$ Department of Medical Research and Education, Taipei Veterans General Hospital, Taipei 11217, Taiwan \\ ${ }^{5}$ Institute of Clinical Medicine, National Yang-Ming University, Taipei 112, Taiwan \\ ${ }^{6}$ Department of Surgery, Taipei Veterans General Hospital, Taipei 11217, Taiwan \\ ${ }^{7}$ Department of Pharmacy Practice, Tri-Service General Hospital and 114 National Defense Medical Center, Taipei, Taiwan
}

Correspondence should be addressed to Shih Hwa Chiou, shchiou@vghtpe.gov.tw

Received 28 May 2010; Accepted 15 August 2010

Academic Editor: Eric Deutsch

Copyright (๑) 2011 Cheng-Chia Yu et al. This is an open access article distributed under the Creative Commons Attribution License, which permits unrestricted use, distribution, and reproduction in any medium, provided the original work is properly cited.

\begin{abstract}
Recent studies suggest that ALDH1 is a putative marker for HNSCC-derived cancer stem cells. However, the regulation mechanisms that maintain the stemness and metastatic capability of HNSCC-ALDH1 ${ }^{+}$cells remain unclear. Initially, HNSCC-ALDH1 ${ }^{+}$cells from HNSCC patient showed cancer stemness properties, and high expression of Bmil and Snail. Functionally, tumorigenic properties of HNSCC-ALDH1 ${ }^{+}$cells could be downregulated by knockdown of Bmi-1. Overexpression of Bmi- 1 altered in expression property ALDH1 $1^{-}$cells to that of $\mathrm{ALDH}^{+}$cells. Furthermore, knockdown of Bmi- 1 enhanced the radiosensitivity of radiation-treated HNSCC-ALDH1 ${ }^{+}$cells. Moreover, overexpression of Bmi-1 in HNSCC-ALDH1 ${ }^{-}$cells increased tumor volume and number of pulmonary metastatic lesions by xenotransplant assay. Importantly, knock-down of Bmil in HNSCC-ALDH1 ${ }^{+}$ cells significantly decreased distant metastases in the lungs. Clinically, coexpression of Bmi-1/Snail/ALDH1 predicted the worst prognosis in HNSCC patients. Collectively, our data suggested that Bmi-1 plays a key role in regulating Snail expression and cancer stemness properties of HNSCC-ALDH1 ${ }^{+}$cells.
\end{abstract}

\section{Introduction}

Head and neck squamous cell carcinoma (HNSCC), including oral squamous cell carcinoma (OSCC), is the sixth most prevalent type of malignancy worldwide and accounts for approximately $8 \%$ to $10 \%$ of all cancers in Southeast Asia $[1,2]$. HNSCC-related mortality is mainly caused by cervical lymph node metastasis, and occasionally by distant organ metastasis [3].

The epithelial-mesenchymal transition (EMT) is a process in which epithelial cells lose their polarity and adopt a mesenchymal phenotype [4]. This process is thought to be a critical step in the induction of tumor metastasis and malignancy [5]. Mani et al. demonstrated that induction of EMT results in cells that have stem cell properties and generates cells with properties similar to breast cancer stem cells [6]. Snail, a member of the zinc-finger transcription factor family, is one of the master regulators that promotes EMT and mediates invasiveness as well as metastasis in many different types of malignant tumors $[7,8]$. The aldehyde dehydrogenase (ALDH) family of enzymes is comprised of cytosolic isoenzymes that oxidize intracellular aldehydes and contribute to the oxidation of retinol to retinoic acid in early stem cell differentiation [9]. Recently, ALDH has been reported to be a unique marker of head and neck cancer stem cells (CSC) $[10,11]$. ALDH1 was also found to co-localize with other CSCs-related markers, including MMP-9, CD44, and CK14, at the invasive front of the tumor [12]. We previously 
TABLE 1: Case description, tumorigenic characteristics and treatment effects of ALDH1 ${ }^{+}$and ALDH1- ${ }^{-} \mathrm{HNCC}$

\begin{tabular}{|c|c|c|c|c|c|c|c|c|}
\hline \multirow[b]{2}{*}{ Case } & \multirow[b]{2}{*}{ Age/Sex } & \multirow[b]{2}{*}{$\mathrm{ALDH}^{+}(\%)$} & \multirow[b]{2}{*}{$\begin{array}{c}\text { Spheres } \\
\text { Formation }\end{array}$} & \multicolumn{5}{|c|}{ Number of cells injected } \\
\hline & & & & Parental & $\mathrm{ALDH}^{+}$ & $\mathrm{ALDH}^{+}(\mathrm{Sh}-\mathrm{Bmi} 1)$ & $\mathrm{ALDH}^{-}$ & $\mathrm{ALDH1}^{-}$(Bmi 1Over) \\
\hline \multirow[t]{3}{*}{1} & $71 / \mathrm{M}$ & 44.2 & Yes & $1,000(0 / 3)$ & $1,000(1 / 3)$ & $1,000(0 / 3)$ & $1,000(0 / 3)$ & $1,000(1 / 3)$ \\
\hline & & & & $3,000(0 / 3)$ & $3,000(3 / 3)$ & $3,000(0 / 3)$ & $3,000(0 / 3)$ & $3,000(1 / 3)$ \\
\hline & & & & $10,000(1 / 3)$ & $10,000(3 / 3)$ & $10,000(2 / 3)$ & $10,000(1 / 3)$ & $10,000(2 / 3)$ \\
\hline \multirow[t]{3}{*}{2} & $73 / \mathrm{F}$ & 24.7 & Yes & $1,000(0 / 3)$ & $1,000(1 / 3)$ & $1,000(1 / 3)$ & $1,000(0 / 3)$ & $1,000(0 / 3)$ \\
\hline & & & & $3,000(0 / 3)$ & $3,000(2 / 3)$ & $3,000(2 / 3)$ & $3,000(0 / 3)$ & $3,000(1 / 3)$ \\
\hline & & & & $10,000(2 / 3)$ & $10,000(2 / 3)$ & $10,000(2 / 3)$ & $10,000(0 / 3)$ & $10,000(2 / 3)$ \\
\hline \multirow[t]{3}{*}{3} & $61 / F$ & 8.6 & Yes & $1,000(0 / 3)$ & $1,000(1 / 3)$ & $1,000(1 / 3)$ & $1,000(0 / 3)$ & $1,000(0 / 3)$ \\
\hline & & & & $3,000(0 / 3)$ & $3,000(3 / 3)$ & $3,000(1 / 3)$ & $3,000(0 / 3)$ & $3,000(2 / 3)$ \\
\hline & & & & $10,000(0 / 3)$ & $10,000(3 / 3)$ & $10,000(2 / 3)$ & $10,000(0 / 3)$ & $10,000(3 / 3)$ \\
\hline \multirow[t]{3}{*}{4} & $71 / \mathrm{M}$ & 1.2 & Yes & $1,000(0 / 3)$ & $1,000(0 / 3)$ & $1,000(0 / 3)$ & $1,000(0 / 3)$ & $1,000(0 / 3)$ \\
\hline & & & & $3,000(0 / 3)$ & $3,000(3 / 3)$ & $3,000(0 / 3)$ & $3,000(0 / 3)$ & $3,000(2 / 3)$ \\
\hline & & & & $10,000(0 / 3)$ & $10,000(3 / 3)$ & $10,000(2 / 3)$ & $10,000(0 / 3)$ & $10,000(3 / 3)$ \\
\hline \multirow[t]{3}{*}{5} & $69 / M$ & 19.2 & Yes & $1,000(0 / 3)$ & $1,000(1 / 3)$ & $1,000(0 / 3)$ & $1,000(0 / 3)$ & $1,000(0 / 3)$ \\
\hline & & & & $3,000(0 / 3)$ & $3,000(3 / 3)$ & $3,000(1 / 3)$ & $3,000(0 / 3)$ & $3,000(2 / 3)$ \\
\hline & & & & $10,000(1 / 3)$ & $10,000(3 / 3)$ & $10,000(2 / 3)$ & $10,000(0 / 3)$ & $10,000(3 / 3)$ \\
\hline \multirow[t]{3}{*}{6} & $72 / \mathrm{M}$ & 5.5 & Yes & $1,000(0 / 3)$ & $1,000(1 / 3)$ & $1,000(0 / 3)$ & $1,000(0 / 3)$ & $1,000(0 / 3)$ \\
\hline & & & & $3,000(0 / 3)$ & $3,000(3 / 3)$ & $3,000(1 / 3)$ & $3,000(0 / 3)$ & $3,000(2 / 3)$ \\
\hline & & & & $10,000(0 / 3)$ & $10,000(3 / 3)$ & $10,000(1 / 3)$ & $10,000(0 / 3)$ & $10,000(2 / 3)$ \\
\hline
\end{tabular}

$\mathrm{ALDH}^{+}$: ALDH1-positive HNSCC cells; ALDH1 ${ }^{-}$: ALDH1-negative HNSCC cells.

$\mathrm{ALDH}^{+}$or $\mathrm{ALDH}^{+}{ }^{+}$cells were injected into neck of SCID mice.

reported the isolation of ALDH1-positive cells from patients with HNSCC [13]. These HNSCC-ALDH1 ${ }^{+}$cells displayed the radioresistance and represented a reservoir of cells that have the proliferative potential to generate tumors [13]. ALDH $1^{+}$-lineage cells underwent EMT and endogenously co-expressed Snail [13]. These findings suggested that Snail expression may regulate the tumorigenesis, radiochemoresistance, and cancer stem cell properties of malignant HNSCC tumors [13]. However, the molecular mechanisms involved in mediating metastasis and tumor malignancy of HNSCCCSC through the regulation of Snail remain unknown.

Bmi-1 is a member of the Polycomb (PcG) family of transcriptional repressors that mediate gene silencing by regulating chromatin structure [14]. Bmi-1 is essential for maintaining the ability of neural, hematopoietic, and intestinal stem cells to self-renew [15-17]. Bmi-1 was identified as a proto-oncogene that cooperates with MYC to promote the generation of lymphoma [18]. Bmi-1 also inhibited MYC-induced apoptosis by repressing the Cdkn2a locus [19]. Additionally, Bmi-1 has been verified as a predictor of prognosis in bladder cancer [20], prostate cancer [21], brain cancer [22, 23], breast cancer [24], pancreatic cancer [25], and lung cancer [26]. Bmi-1 has been demonstrated to play a role in the tumorigenesis of HNSCC [27, 28]. Bmi-1 has also been reported to be involved in tumor metastasis $[29,30]$. Recently, an elegant study by Song et al. showed that Bmi-1 can directly promote EMT and malignancy in nasopharyngeal carcinoma by regulating Snail [31]. The goal of this study was to clarify the relationship between Bmi-1,
Snail, and ALDH1 in HNSCC or HNSCC-associated CSC and the involved molecular mechanisms.

\section{Materials and Methods}

2.1. Isolation and Cultivation of HNSCC-Derived ALDH1 ${ }^{+}$ and ALDH1 ${ }^{-}$Cells from HNSCC Patients. This study followed the tenets of the Declaration of Helsinki. All samples were obtained after patients provided informed consent. The study was approved by the Institutional Ethics Committee/Institutional Review Board of Taipei Veterans General Hospital. The information of HNSCC patients has been previously described in Table 1 . The dissociated cells from the samples of HNSCC patients were suspended at $1 \times$ $10^{6} \mathrm{cells} / \mathrm{mL}$ in $37^{\circ} \mathrm{C}$ DMEM supplemented with $2 \%$ FCS. The identification of aldehyde dehydrogenase 1 (ALDH1) positive HNSCC cells was carried out using the Aldefluor assay (StemCell Technologies, Durham, NC, USA) and fluorescence-activated cell sorting. Cells were suspended in ALDEFLUOR assay buffer containing ALDH substrate (BAAA, $1 \mu \mathrm{mol} / 1$ per $1 \times 10^{6}$ cells) and incubated for $40 \mathrm{~min}$ at $37^{\circ} \mathrm{C}$. As a negative control, for each sample of cells, an aliquot was treated with $50 \mathrm{mmol} / \mathrm{l}$ diethylaminobenzaldehyde (DEAB), a specific ALDH inhibitor. The sorting gates were established using the cells stained with PI only as a negative control; the ALDEFLUOR-stained cells treated with DEAB and staining with a secondary antibody alone to test for viability. HNSCC-ALDH1 ${ }^{+}$cells were cultured in a medium consisting of serum-free DMEM/F12 
TABLE 2: The sequences for the primers of quantitative RT-PCR.

\begin{tabular}{|c|c|c|c|}
\hline Gene(Accession No.) & Primer Sequence $\left(5^{\prime}\right.$ to $\left.3^{\prime}\right)$ & Product size (bp) & $\operatorname{Tm}\left({ }^{\circ} \mathrm{C}\right)$ \\
\hline \multirow{2}{*}{ Oct-4(NM_002701) } & F: GTGGAGAGCAACTCCGATG & \multirow{2}{*}{86} & \multirow{2}{*}{60} \\
\hline & R: TGCTCCAGCTTCTCCTTCTC & & \\
\hline \multirow{2}{*}{ Nanog(NM_024865) } & F: ATTCAGGACAGCCCTGATTCTTC & \multirow{2}{*}{76} & \multirow{2}{*}{60} \\
\hline & R: TTTTTGCGACACTCTTCTCTGC & & \\
\hline \multirow{2}{*}{ SOX-2(NM_003106) } & F: CGAGTGGAAACTTTTGTCGGA & \multirow{2}{*}{74} & \multirow{2}{*}{60} \\
\hline & R: TGTGCAGCGCTCGCAG & & \\
\hline \multirow{2}{*}{ Musashi(NM_002442) } & F: TCCCTCGGCGAGCACA & \multirow{2}{*}{64} & \multirow{2}{*}{60} \\
\hline & R: GACAGCCCCCCCACAAA & & \\
\hline \multirow{2}{*}{ c-Myc(NM_002467) } & F: GGAACGAGCTAAAACGGAGCT & \multirow{2}{*}{71} & \multirow{2}{*}{55} \\
\hline & R: GGCCTTTTCATTGTTTTCCAACT & & \\
\hline \multirow{2}{*}{$\beta$-catenin(NM_001904) } & F: CCAGCCGACACCAAGAAG & \multirow{2}{*}{130} & \multirow{2}{*}{55} \\
\hline & R: CGAATCAATCCAACAGTAGCC & & \\
\hline \multirow{2}{*}{ Bmil(NM_ 005180) } & F?AAATGCTGGAGAACTGGAAAG & \multirow{2}{*}{124} & \multirow{2}{*}{50} \\
\hline & R?CTGTGGATGAGGAGACTGC & & \\
\hline \multirow{2}{*}{ Nestin(NM_006617) } & F: AGGAGGAGTTGGGTTCTG & \multirow{2}{*}{112} & \multirow{2}{*}{50} \\
\hline & R: GGAGTGGAGTCTGGAAGG & & \\
\hline \multirow{2}{*}{ Snail(NM_005985) } & F:GCTGCCAATGCTCATCTGGGACTCT & \multirow{2}{*}{300} & \multirow{2}{*}{55} \\
\hline & R: TTGAAGGGCTTTCGAGCCTGGAGAT & & \\
\hline \multirow{2}{*}{ Slug(NM_003068) } & F: GTGATTATTTCCCCGTATCTCTAT & \multirow{2}{*}{292} & \multirow{2}{*}{50} \\
\hline & R: CAATGGCATGGGGGTCTGAAAG & & \\
\hline \multirow{2}{*}{ MDR-1 (NM_000927) } & F: TGGCAAAGAAATAAAGCGACTGA & \multirow{2}{*}{76} & \multirow{2}{*}{60} \\
\hline & R: CAGGATGGGCTCCTGGG & & \\
\hline MRP-1(X60111) & F: GCTTCCTCTTGGTGATATTCG & 176 & 50 \\
\hline МIRP-I(XОU111) & R: GCAGTTCAACGCATAGTGG & 170 & 50 \\
\hline ABCG2(NM 004827) & F: CATGTACTGGCGAAGAATATTTGGT & 74 & 60 \\
\hline ADCGL(NIV_004827) & R: CACGTGATTCTTCCACAAGCC & $/ 4$ & 00 \\
\hline GAPDH(NM_002046) & F: CATCATCCCTGCCTCTACTG & 180 & 60 \\
\hline UAPDН(NVI_UOZU4O) & R: GCCTGCTTCACCACCTTC & 100 & 00 \\
\hline
\end{tabular}

(Gibco-BRL, Gaithersburg, MD), N2 supplement ( $\mathrm{R}$ and D Systems Inc., Minneapolis), $10 \mathrm{ng} / \mathrm{mL}$ bFGF (R and D Systems), and $10 \mathrm{ng} / \mathrm{mL}$ EGF (R and D Systems) [13, 32].

2.2. Quantitative Real-Time RT-PCR. Briefly, total RNA $(1 \mu \mathrm{g})$ of each sample was reverse-transcribed using $0.5 \mu \mathrm{g}$ oligo dT and $200 \mathrm{U}$ Superscript II RT (Invitrogen). The primer sequences for real-time RT-PCR were listed in Table 2. The amplification was carried out in a total volume of $20 \mu \mathrm{L}$ containing $0.5 \mu \mathrm{mol} \cdot \mathrm{L}^{-1}$ of each primer, $4 \mathrm{mmol} \cdot \mathrm{L}^{-1} \mathrm{MgCl} 2,2 \mu \mathrm{L}$ LightCyclerTM-FastStart DNA Master SYBR green I (Roche Molecular Systems, Alameda, $\mathrm{CA})$, and $2 \mu \mathrm{L}$ of $1: 10$ diluted cDNA. PCR reactions were prepared in duplicate and performed using the following program: $95^{\circ} \mathrm{C}$ for $10 \mathrm{~min}$, followed by 40 cycles of denaturation at $95^{\circ} \mathrm{C}$ for $10 \mathrm{sec}$, annealing at $55^{\circ} \mathrm{C}$ for $5 \mathrm{sec}$, and extension at $72^{\circ} \mathrm{C}$ for $20 \mathrm{sec}$. Standard curves (cycle threshold values versus template concentration) were prepared for each target gene and for the endogenous reference gene (GAPDH) for each sample. Quantification of unknown samples was performed using LightCycler Relative Quantification Software version 3.3 (Roche).

2.3. Knockdown and Overexpression of Bmi-1 with Lentivirus. The pLVRNAi vector was purchased from Biosettia Inc. (Biosettia, San Diego CA). The oligonucleotide 5'-AAAACCTAATACTTTCCAGATTGATTTGGATCCAAATCAATCTGGAAAGTATTAGG-3' targeting human Bmi-1 (NM_005180, nt 1061-1081) was synthesized and cloned into pLVRNAi to generate the lentiviral expression vector, pLVRNAi/sh-Bmil. The lentiviral expression vector carrying Bmi-1 full-length cDNA, pLV/Bmi-1 was obtained from Biosettia Inc. pCMV $\Delta$ R8.9 and pMD.G, expressing GAGPOL and the vesicular stomatitis virus envelope, respectively, were provided by the consortium (Academia Sinica, Taipei, Taiwan). The lentiviruses were generated by cotransfecting 
$5 \times 10^{6} 293 \mathrm{FT}$ cells per $10 \mathrm{~cm}$ plate with lentiviral vector and packaging plasmids using Lipofectamine 2000 (LF2000, Invitrogen). Supernatants were collected 48 hours after transfection and filtered. The 48 -hour posttransduction viral titers were determined by FACS. Subconfluent cells were infected with lentivirus at a multiplicity of infection of 5 in the presence of $8 \mu \mathrm{g} / \mathrm{mL}$ polybrene (Sigma-Aldrich) $[13,33]$.

2.4. Microarray Analysis and Bioinformatics. Total RNA was extracted from cells using Trizol reagent (Life Technologies, Bethesda, MD, USA) and the Qiagen RNAeasy (Qiagen, Valencia, CA, USA) column for purification. Affymetrix HG U133 Plus 2.0 microarrays containing 54,675 probe sets for $>47,000$ transcripts and variants, including 38,500 human genes. A typical probeset contains eleven 25-mer oligo nucleotide pairs (a perfect match and a mismatch control). For microarray analysis, sample labeling, hybridization, and staining were carried out by Affymetrix standard protocol with affyQCReport. Probeset was normalized with loess method of all microarrays. The average linkage distance was used to assess the similarity between two groups of gene expression profiles as described below. The difference in distance between two groups of sample expression profiles to a third was assessed by comparing the corresponding average linkage distances (the mean of all pairwise distances (linkages) between members of the two groups concerned). The error of such a comparison was estimated by combining the standard errors (the standard deviation of pairwise linkages divided by the square root of the number of linkages) of the average linkage distances involved. Classical multidimensional scaling (MDS) was performed using the standard function of the $\mathrm{R}$ program to provide $\mathrm{a}$ visual impression of how the various sample groups are related.

2.5. In Vivo Tumor Growth and Metastasis. All procedures involving animals were in accordance with the institutional animal welfare guidelines of Taipei Veterans General Hospital. Eight-week-old SCID mice and/or nude mice (BALB/c strain) were injected with 105 cells orthotopically. In vivo GFP imaging was performed using an illuminating device (LT-9500 Illumatool/TLS equipped with an excitation source $(470 \mathrm{~nm})$ and filter plate $(515 \mathrm{~nm}))$. Tumor size was measured with calipers and the tumor volume was calculated using the formula (Length $\times$ Width2)/2. The integrated optical density of green fluorescence intensity was captured and analyzed using Image Pro-plus software [33, 34].

2.6. Statistical Analysis. The Statistical Package of Social Sciences software (SPSS, Inc., Chicago, IL) was used for statistical analysis. An independent Student's $t$-test was used to compare the continuous variables between groups. The Kaplan-Meier procedure was used to calculate survival probability estimates. A log-rank test was used to compare the cumulative survival durations in different patient groups. The statistical significance level was set at 0.05 for all tests.

\section{Results}

3.1. HNSCC-Derived ALDH1-Positive Cells Displayed Tumorigenic and Stemness Properties. Initially, parental, isolated $\mathrm{ALDH}_{1}{ }^{+}$, and $\mathrm{ALDH}^{-}$cells were isolated from tissue samples of six HNSCC patients using the Aldefluor assay and the fluorescence-activated cell sorting (FACS) analysis (Figure 1(a) and Table 1) [13, 35]. It has been reported that cancer stem-like cells can be cultured in suspension to generate floating spheroidlike bodies (SB) under serum-free medium with bFGF and EGF [36]. Interestingly, ALDH1 ${ }^{+}$increased higher tumor spheres-forming capability than that of ALDH1 ${ }^{-}$ (Figure 1(b)). Furthermore, ALDH1 ${ }^{+}$-derived spheres with regular $10 \%$ serum cultivation increased epithelialattached cells and differentiation marker (CK18)(See Figure 1(a) in supplementary material available online at doi: $10.1155 / 2011 / 609259)$. To evaluate the enhancement of tumorigenicity of HNSCC-ALDH1 ${ }^{+}$cells, soft agar colony formation assays and Matrigel/Transwell-invasion and were examined. Compared with parental and $\mathrm{ALDH1}^{-}, \mathrm{ALDH}^{+}$ derived from HNSCC Patients no. 1 and no. 2 showed colony-forming ability and higher invasion activity (Figures $1(\mathrm{c})$ and $1(\mathrm{~d})$ ). To evaluate the in vivo tumor initiating capability of $\mathrm{ALDH}_{1}^{+}$and $\mathrm{ALDH}^{-}$, we injected 1000, 3000 , and $10^{4}$ cells into the neck of SCID mice. The results showed that $104 \mathrm{ALDH}^{-}$did not induce tumor formation but 3,000 ALDH1 ${ }^{+}$from the HNSCC tissues of six patients in xenotransplanted mice all resulted in the generation of visible tumors 6 weeks after injection (Table 1). The results of xenotransplanted analysis further showed that $\mathrm{ALDH}^{+}{ }^{+}$demonstrated higher abilities to induce tumor growth (Figure 1(e)). Lastly, serial xenotransplanted analysis suggested that $\mathrm{ALDH1}^{+}$had in vivo self-renewal ability (Supplementary Figure 1(b)). Based on these findings, the ALDH1 ${ }^{+}$-lineage cells isolated from HNSCC patients presented the significant tumor-initiating abilities, especially in $\mathrm{ALDH}_{1}{ }^{+}$cells from patients no. 1 and no. 2. Real-time RTPCR data demonstrated that the stemness and EMT-related genes (especially in Bmi-1 and Snail) were significantly activated in HNSCC ALDH1 $^{+}$(Table 2 and data not shown).

3.2. Knockdown of Bmi-1 in HNSCC-ALDH1 ${ }^{+}$Cells DownRegulates Snail and Lessens in vitro Tumorigenicity. To further investigate the role of Bmi-1 in maintaining the biological properties of HNSCC-ALDH1 ${ }^{+}$, we used a loss-of-function approach, in which Bmi-1 was knocked down by small hairpin RNA (shRNA) in HNSCC-ALDH1 ${ }^{+}$ cells. Stable knockdown of Bmi-1 in HNSCC-ALDH1 ${ }^{+}$ cells was achieved by transduction with lentivirus that expressed shRNA targeting Bmi-1 (sh-Bmi-1). Lentivirus that expressed shRNA targeted against luciferase (sh-Luc.) was used as a control. Western blot analysis confirmed that shBmi-1 repressed Bmi-1 protein expression in HNSCC$\mathrm{ALDH}^{+}{ }^{+}$cells (Figure 2(a)). Importantly, silencing Bmi-1 expression led to downregulation of Snail and ALDH1 expression (Figure 2(a)). Additionally, our results showed that silencing of Bmi-1 in HNSCC-ALDH1 ${ }^{+}$cells inhibited 

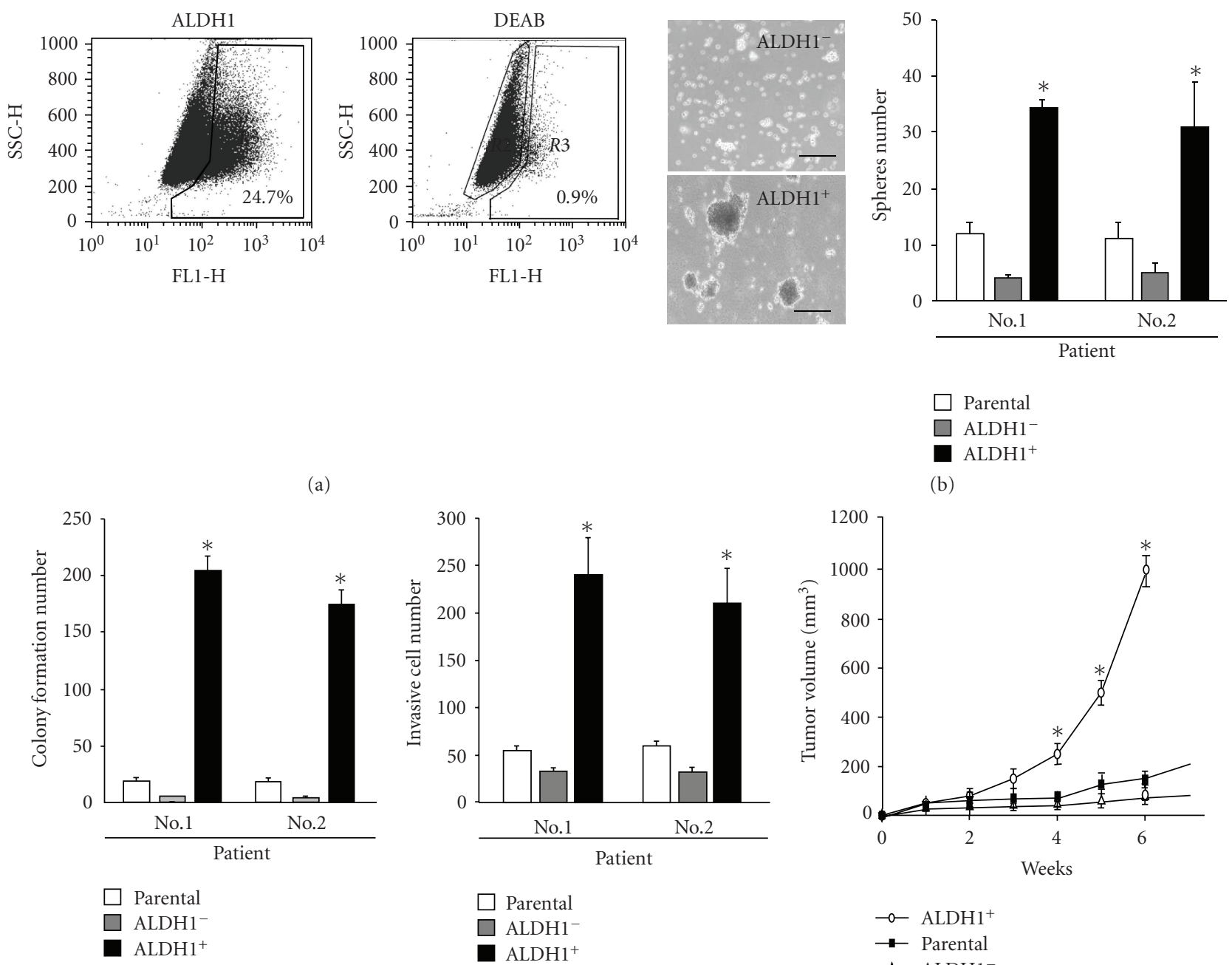

(c)

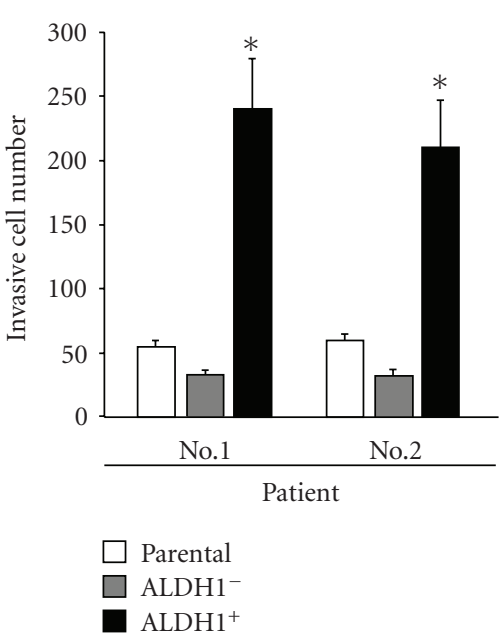

(d)

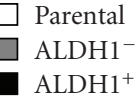

(b)

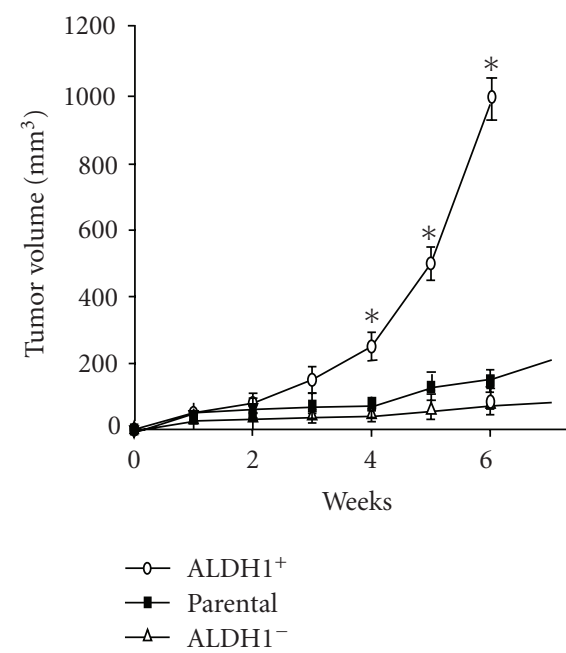

(e)

Figure 1: Isolation and Characterization of HNSCC-derived ALDH1-positive Cells. (a) Analyzing and sorting ALDH1 ${ }^{+}$-positive and $\mathrm{ALDH}^{-}{ }^{-}$-negative from HNSCC tissues via FACScan. DEAB, an inhibitor of ALDH1, was used for negative control. (b) Evaluation of sphere body formation in the parental cells, ALDH1 ${ }^{-}$cells, and ALDH1 ${ }^{+}$cells. Sphere bodies were counted after 1 week. The numbers of resultant colonies (c) and invasion cells (d) from parental cells, ALDH1 ${ }^{+}$cells, and ALDH1 ${ }^{-}$cells were counted in vitro. (e) Macroscopic features of cells in a nude mouse at 6 weeks after xenotransplantation. Blue arrow indicates the site of injection of ALDH1- cells. Red arrow indicates the site of injection of ALDH1 ${ }^{+}$cells. Yellow arrow indicates the site of injection of ALDH1 ${ }^{+}$cells. ${ }^{*} P<.05$. Data shown here are the mean \pm $\mathrm{SD}$ of three experiments.

the ability of the cells to form colonies on soft agar (Figure 2(b)) and migrate/invade (Figure 2(c)).

\subsection{Overexpression of Bmi-1 in HNSCC-ALDH1 ${ }^{-}$Cells} Enhances Tumorigenic Properties by Upregulating Snail. To evaluate whether overexpression of Bmi-1 could enhance the tumorigenic properties of HNSCC-ALDH1 ${ }^{-}$cells, we generated stable Bmi-1-overexpressing (Bmi-1Over) HNSCCs using lentiviral transduction (Figure 2(d)). Total proteins from HNSCC-ALDH1 ${ }^{-}$overexpressing Bmi-1 exhibited elevated expression of Snail and ALDH1 (Figure 2(d)). In addition, overexpression of Bmi-1 significantly increased soft agar colony formation (Figure 2(e)), and migration/invasion of HNSCC-ALDH ${ }^{-}$cells (Figure 2(f)). Taken together, our results suggest that $\mathrm{Bmi}-1$ modulates the in vitro tumorigenic properties in $\mathrm{HNSCC}_{-\mathrm{ALDH} 1^{+}}$or $\mathrm{ALDH}^{-}$cells by regulating Snail.

\subsection{Overexpression of Bmi-1 in HNSCC-ALDH1- Cells Pro-} motes Stemness Properties. To explore molecules governing stemness and tumorigenicity in HNSCC-CD44- ${ }^{-}$LDH1 ${ }^{-}$ cells treated with Bmil-overexpressing lentivirus, we examined their transcriptome profile using gene expression microarray analysis (Figure 3(a)). Principle component analysis (PCA) further showed that the transcriptome profile of HNSCC-ALDH1 ${ }^{-}$cells overexpressing Bmi-1 demonstrated higher expression levels of embryonic stem cells (ESCs) transcriptomes (Table 3 and Figure 3(b)). Multidimensional 


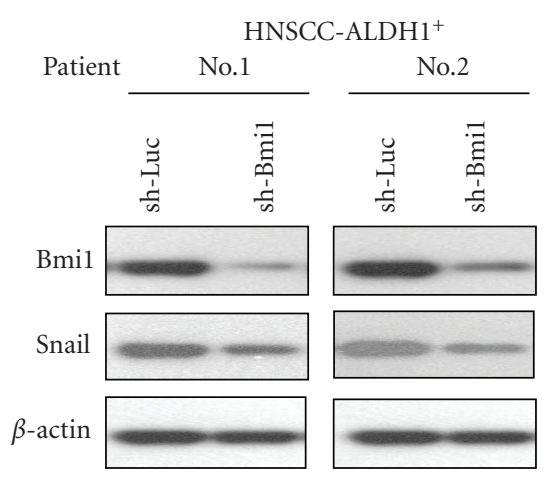

(a)

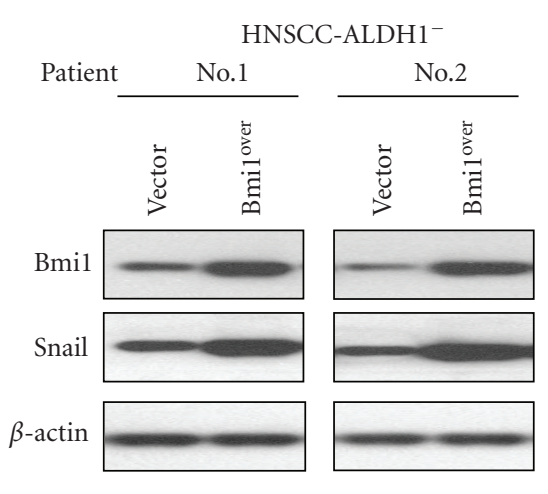

(d)

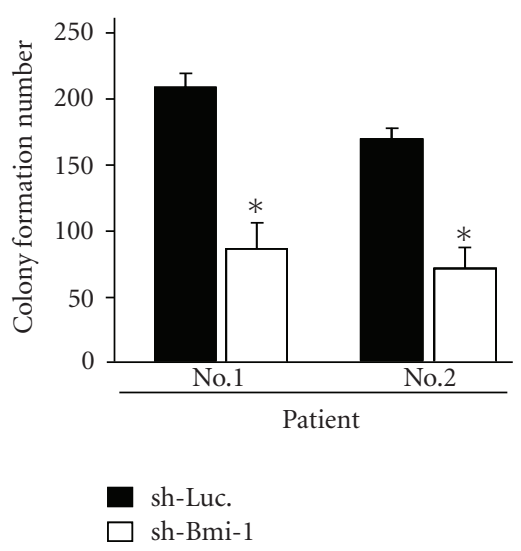

(b)

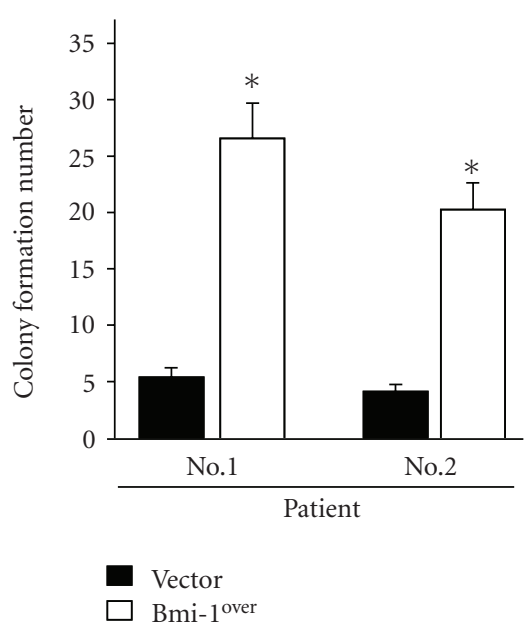

(e)

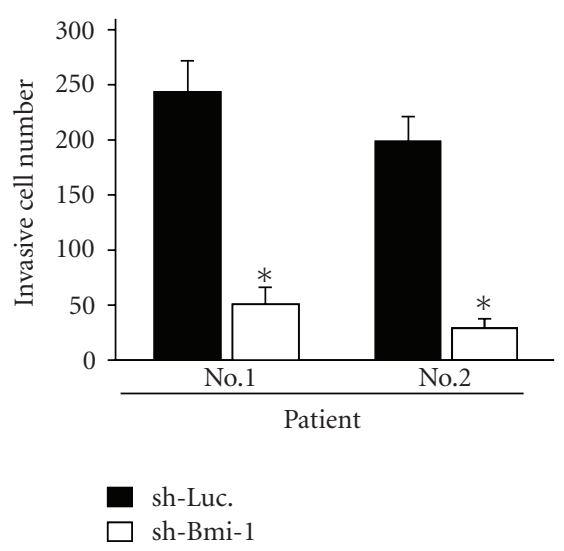

(c)

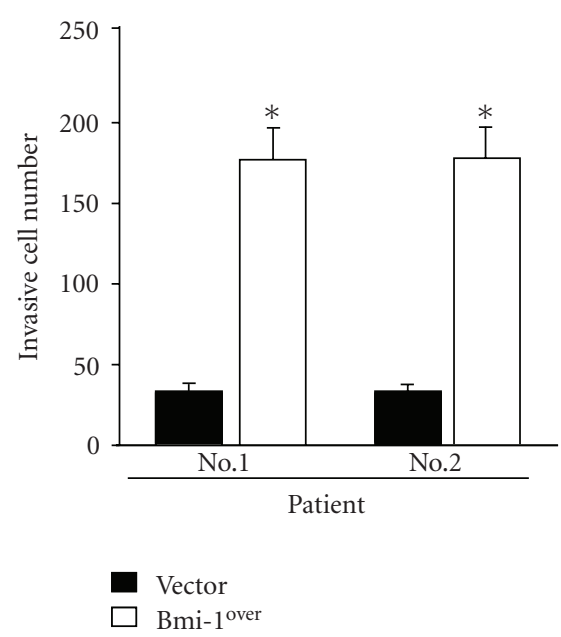

(f)

FIGURE 2: Overexpression of Bmi-1 in HNSCC-ALDH1 ${ }^{-}$cells or knockdown of Bmi-1 in HNSCC-ALDH ${ }^{+}$cells modulates Snail expression and tumorigenicity in vitro. (a) Down-regulation of Bmi-1 mediated by lentiviral shRNA and expression of Snail and ALDH1 in HNSCC$\mathrm{ALDH}^{+}$cells was analyzed by western blot. Colony formation (b) and migration/invasion ability (c) of shLuc.-expressing and shBmi-1expressing HNSCC-ALDH1 ${ }^{+}$cells was determined. (d) Total protein was prepared from control GFP-expressing andBmi-1-overexpressing HNSCC-ALDH1 ${ }^{-}$cells and analyzed by immunoblotting with anti-Bmi-1, anti-Snail, anti-ALDH1, or anti-GAPDH antibodies as indicated. The amount of GAPDH protein from each crude cell extract was used as loading control. Colony formation (e) and migration/invasion ability (f) of Bmi-1-overexpressing and control-GFP-expressing HNSCC-ALDH1 ${ }^{-}$were analyzed. ${ }^{*} P<.05$. Data shown here are the mean $\pm \mathrm{SD}$ of three experiments.

scaling analysis further demonstrated that HNSCC-ALDH $1^{+}$ cells and HNSCC-ALDH1 ${ }^{-}$cells overexpressing Bmi- 1 are more similar to ESCs than HNSCC-ALDH $1^{-}$cells $\left({ }^{*} P<.05\right.$; Figure $3(\mathrm{c})$ ). To validate the microarray analysis results, realtime PCR was performed to confirm that the mRNA expression levels of the embryonic genes (Oct-4, Nanog, Sox2, KLF4, and Lin28), EMT-related genes (Snail and Slug), and drug-resistant-related genes (MDR-1 and ABCG2) in Bmi-1overexpressing ALDH1 ${ }^{-}$cells were significantly higher than those in ALDH1 ${ }^{-}$cells $\left({ }^{*} P<.05\right.$; Table 2 and Figure $\left.3(\mathrm{~d})\right)$.

\subsection{Elevation of In Vivo Tumor Growth, Metastatic Activity,} and Radioresistance in HNSCC-ALDH1 ${ }^{-}$Cells by Overexpression of Bmi-1. We next sought to determine if Bmi1 expression could modulate the in vivo tumor initiating activity in immunocompromised nude mice. To monitor the in vivo growth of $\mathrm{ALDH}^{+}, \mathrm{ALDH}^{-}$, and $\mathrm{Bmi}-1-$ overexpressing $\mathrm{ALDH}^{-}$cells, these cells were transfected using a lentivector combined with the green fluorescent protein gene (GFP) and followed by in vivo GFP imaging system. Firstly, the results showed that $1 \times 10^{4} \mathrm{ALDH1}^{-}$ cells did not induce tumor formation in nude mice, but $1000 \mathrm{ALDH}^{+}$cells generated visible tumors 6 weeks after injection (Table 1). In contrast to ALDH1 ${ }^{-}$cells, one of three (33.3\%) nude mice was detected with the tumor formation after 6-week transplantation of $3000 \mathrm{Bmi}$-1-overexpressing ALDH1 ${ }^{-}$cells. Furthermore, tumor volumes in HNSCC$\mathrm{ALDH}_{1}{ }^{+}$transplanted mice were significantly decreased when mice were treated with sh-Bmi-1 (Table 1; Figure 4(a)). Overexpression of Bmi-1 enhanced in vivo tumor growth 


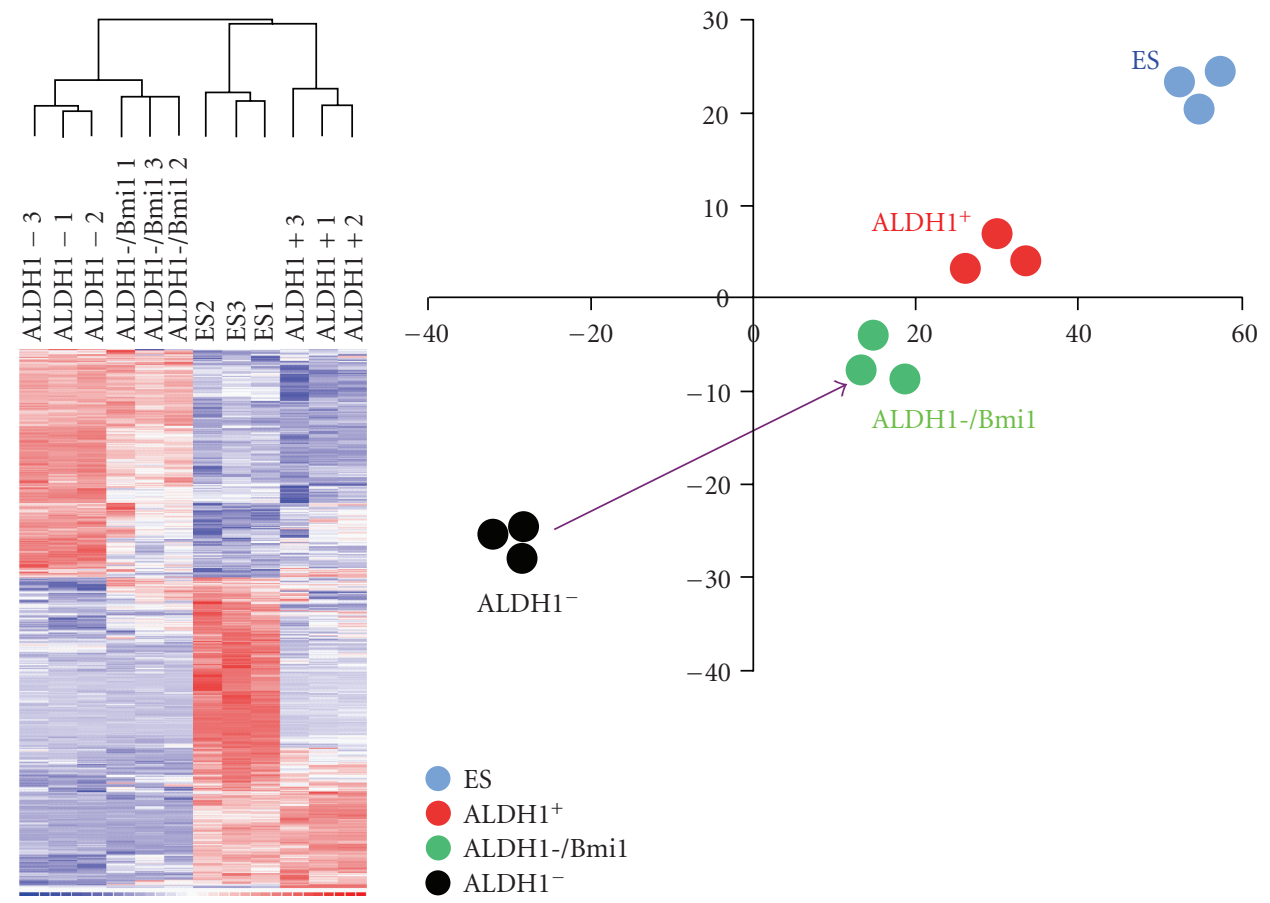

(a)

(b)

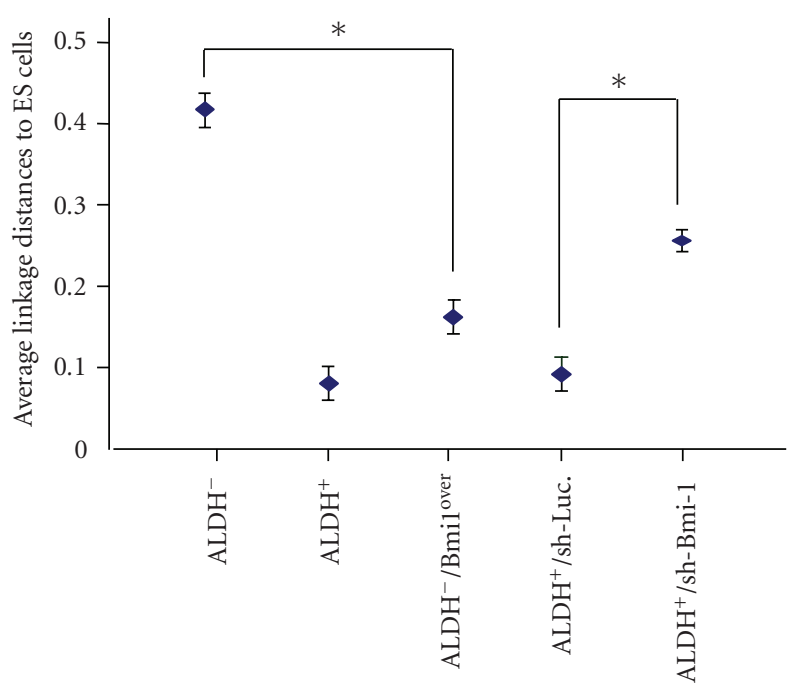

(c)

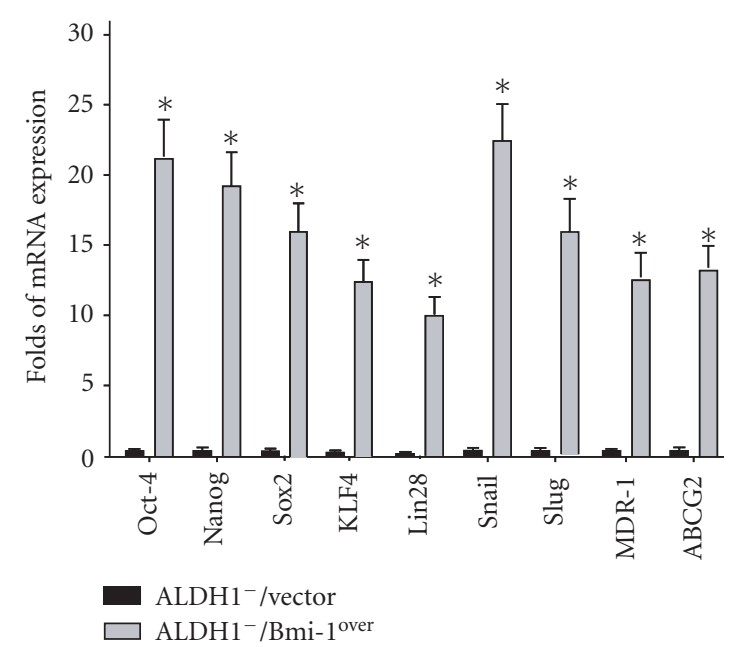

(d)

Figure 3: Stemness properties were enhanced in HNSCC-ALDH1 ${ }^{-}$cells when Bmi-1 was overexpressed. (a) Gene expression microarray analysis (Gene tree) for altered genes differentially expressed in Bmi-1-overexpressing HNSCC-ALDH1- cells compared to HNSCC$\mathrm{ALDH}^{-}$cells by a hierarchy heat map. The time dependent changes of altered genes are presented on a log scale of expression values provided by GeneSpring GX software. (b) Principle component analysis (PCA) demonstrated that overexpression of Bmi-1 in HNSCC$\mathrm{ALDH}^{-}$cells could enhance the gene signature of embryonic stem cells (ESCs) in HNSCC-ALDH1 ${ }^{-}$cells. (c) Multidimensional scaling analysis. Average lineage transcriptome distances between HNSCC-ALDH1 ${ }^{+}, \mathrm{HNSCC}-\mathrm{ALDH} 1^{-}, \mathrm{HNSCC}-\mathrm{ALDH} 1^{+} / \mathrm{sh}^{-B m i-1}$, and HNSCCALDH1 $^{-} /$Bmil $^{\text {over }}$ cells. ${ }^{*} P<.05$. (d) Transcripts of Oct-4, Nanog, Sox2, KLF4, Lin28, Snail, Slug, MDR-1, and ABCG2 in HNSCC-ALDH1 ${ }^{-}$ and HNSCC-ALDH1 ${ }^{-} / \mathrm{Bmi}^{-} 1^{\text {over }}$ cells $\left({ }^{*} P<.05\right.$ : $\mathrm{ALDH}^{-}$versus $\mathrm{Bmi}-1$-overexpressing $\left.\mathrm{ALDH} 1^{-}\right)$.

in $\mathrm{HNSCC}-\mathrm{ALDH}^{-}$(Table 1; Figure 4(a)). Furthermore, we investigated the role of Bmi-1 in the radio sensitivity of ${\mathrm{HNSCC}-\mathrm{ALDH} 1^{-} \text {and HNSCC-ALDH1 }}^{+}$treated with sh-Bmi-1 and Bmi-1 overexpressing. An ionizing radiation (IR) dose of 0 to $10 \mathrm{~Gy}$ was applied to these cells, and
HNSCC-ALDH $1^{+}$cells showed greater radioresistance than the ALDH1 $^{-}$cells $(P<.05$; Figure $4(\mathrm{~b}))$. Knockdown of BMI-1 in $\mathrm{ALDH}^{+}$cells results in significant inhibition of radioresistance while overexpression of BMI-1 in ALDH- cells promotes radioresistant properties $(P<.05$; 


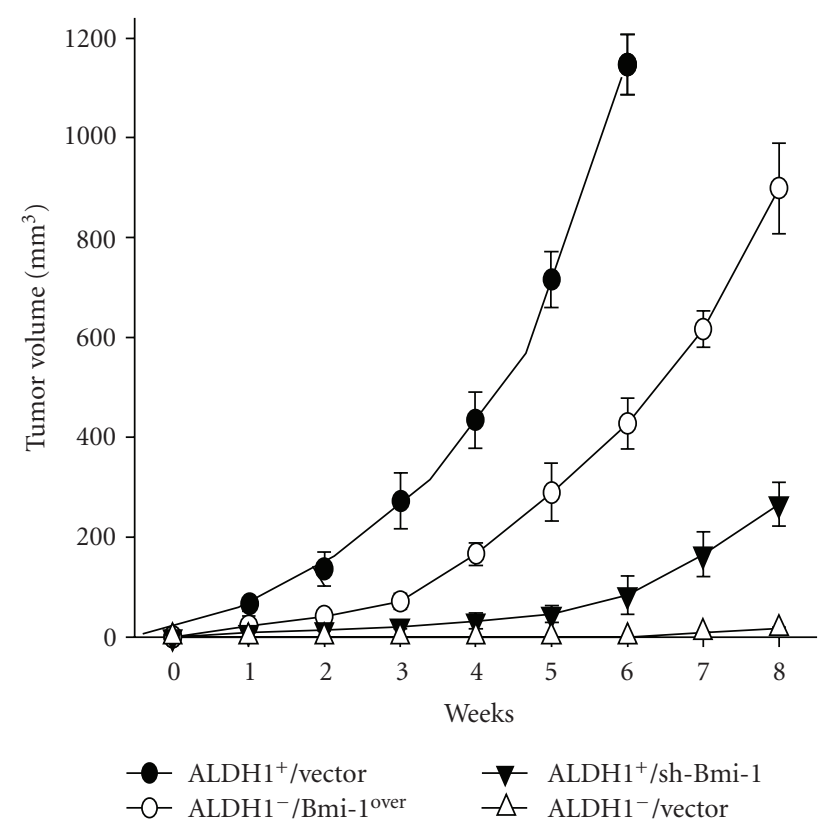

(a)

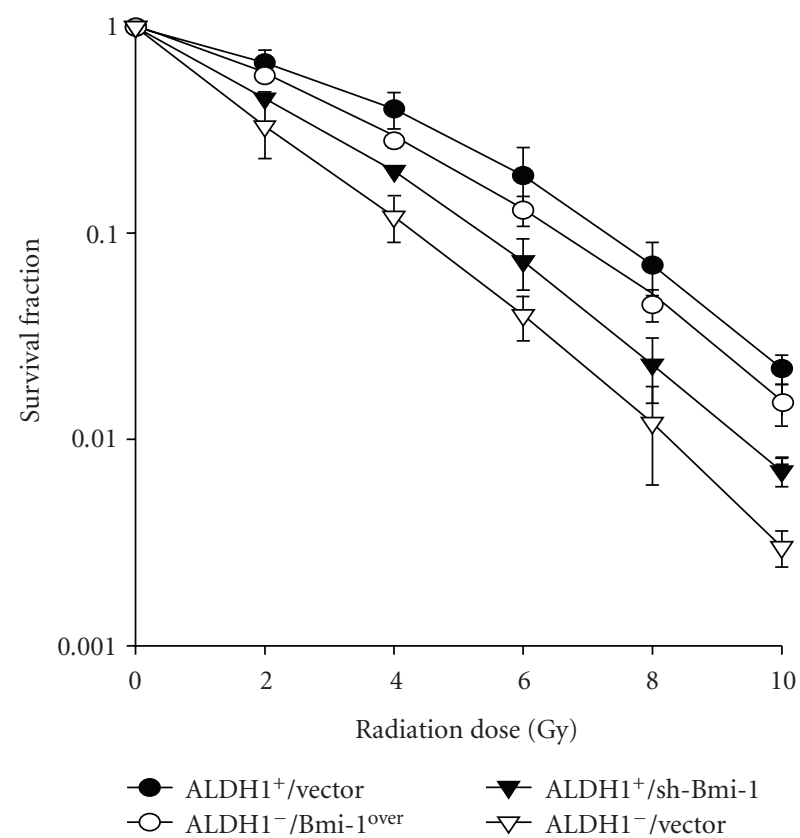

(b)

FIGURE 4: Determination of the role of Bmi-1 on in vivo tumor growth and radioresistance in HNSCC-ALDH1 ${ }^{+}$cells. (a) Tumor volume was measured after injection of either HNSCC-ALDH1 $1^{+}$, sh-Bmi-1 treated HNSCC-ALDH1 ${ }^{+}, \mathrm{HNSCC}-\mathrm{ALDH} 1^{-}$, or Bmi-1-overexpressing HNSCC- ALDH1- cells into the neck of SCID mice. Error bars correspond to SD. (b) To determine the radiation effect on the cell survival rate, an ionizing radiation (IR) dose from 0 to $10 \mathrm{~Gy}$ was used to treated with $\mathrm{ALDH} 1^{+} / \mathrm{vector}, \mathrm{ALDH} 1^{+} / \mathrm{sh}_{-} \mathrm{Bmi}-1, \mathrm{ALDH}^{-} / \mathrm{vector}$, or Bmi-1-overexpressing HNSCC- ALDH1- HNSCC cells.

Figure 4(b)). Moreover, to confirm that Bmi-1 is crucial for metastasis in vivo, mice were injected with different numbers of $\mathrm{ALDH}^{+}, \mathrm{ALDH}^{+} / \mathrm{sh}-\mathrm{Bmi}-1, \mathrm{ALDH}^{-} / \mathrm{Bmi}^{-}$ 1over or control GFP-expressing ALDH1- cells. 5x105 Bmi1-overexpressing ALDH1- cells significantly increased local invasion, distant metastasis to the lungs and tumor size compared with control ALDH1 ${ }^{-}$cells (Figures 5(a) and 5(b)). In addition, silencing Bmi- 1 in $\mathrm{ALDH}^{+}$cells effectively reduced the number of lung metastases and tumor size in vivo (Figures 5(a) and 5(b)). Taken together, our results reveal a crucial role for Bmi-1 signaling in the maintenance of in vivo tumorigenicity and metastasis of HNSCC-ALDH $1^{+}$ and -ALDH1 ${ }^{-}$cells.

3.6. Coexpression of Bmi-1, Snail, and ALDH1 in HNSCC Tissues Correlates with Poor Overall Survival Rate of HNSCC Patients. Elevated Snail protein expression in HNSCC is correlated with the development of metastasis and poor survival [37]. Elevated expression of ALDH1 also correlates with poor prognosis for HNSCC patients [13]. To investigate whether there is a positive correlation between Bmi-1, Snail, and ALDH1 in head and neck cancers, we studied the expression of Bmi-1, Snail, and ALDH1 by immunohistochemical (IHC) staining of a panel of specimens array from 93 HNSCC patients. The IHC results showed that elevated expression of Bmi-1, Snail, and ALDH1 was positively associated with high-grade, poorly differentiated HNSCC (Figure 6(a)). Our results also showed a significant positive correlation between ALDH-1, Bmi-1 (Figure 6(b)); ALDH1 and Snail (Figure 6(c)); Bmi-1 and Snail (Figure 6(d)) in HNSCC tissues. This is consistent with previous studies that reported that HNSCC-ALDH1 ${ }^{+}$cells have elevated Bmi-1 and Snail expression $[13,38]$. To determine the prognostic significance of Bmi-1, Snail, and ALDH1 coexpression in patients with HNSCC, Kaplan-Meier survival analysis was performed. Patients who were triple positive for Bmi-1, Snail, and ALDH1 were predicted to have the worst survival rate compared with other head and neck cancer patients (Figure $6(\mathrm{e})$; $\mathrm{Bmi}^{-} 1^{+} / \mathrm{Snail}^{+} / \mathrm{ALDH} 1^{+}$versus other groups). Overall, these data indicate that expression of Bmi-1, Snail, and ALDH1 in HNSCC patients could be a critical factor in predicting disease progression and clinical outcomes.

\section{Discussion}

A recent study demonstrated that Bmi-1 mRNA and protein overexpressed in a subpopulation of tumor initiating cells in CD44+ HNSCC, which possessed self-renewal and tumor formation ability [39]. Zhang et al. also reported that there are side populations of oral squamous cell carcinomas that express high levels of ABCG2, ABCB1, CD44, Oct-4, Bmi1, NSPc1, and CK19 [28]. Our previous work showed that HNSCC-ALDH1+ cells have high levels of Bmi-1. The ability to self-renew and radiochemoresistance were significantly suppressed in Bmi-1-silenced HNSCC-ALDH1+ cells [38]. Using microarray, western-blotting, and immunofluorescent 
TABLE 3: The expression profiling of up-regulated genes in ALDH1-/Bmil-overexpressed as compared to ALDH1 ${ }^{-} \mathrm{HNSCC}^{-}$

\begin{tabular}{|c|c|c|}
\hline Probe set ID & Gene symbol & Gene title \\
\hline 217757_at & $\mathrm{A} 2 \mathrm{M}$ & alpha-2-macroglobulin \\
\hline 209459_s_at & ABAT & 4-aminobutyrate aminotransferase \\
\hline 213353_at & ABCA5 & ATP-binding cassette, sub-family A (ABC1), member 5 \\
\hline 209993_at & ABCB1(MDR1) & ATP-binding cassette, sub-family B (MDR/TAP), member 1 \\
\hline 214033_at & ABCC6 & ATP-binding cassette, sub-family C (CFTR/MRP), member 6 \\
\hline 210246_s_at & ABCC8 & ATP-binding cassette, sub-family C (CFTR/MRP), member 8 \\
\hline 204567_s_at & ABCG1 & ATP-binding cassette, sub-family G (WHITE), member 1 \\
\hline 209735_at & ABCG2 & ATP-binding cassette, sub-family G (WHITE), member 2 \\
\hline 204151_x_at & AKR1C1 & $\begin{array}{l}\text { aldo-keto reductase family } 1 \text {, member C1 (dihydrodiol dehydrogenase } 1 \text {; } \\
\text { 20-alpha (3-alpha)-hydroxysteroid dehydrogenase) }\end{array}$ \\
\hline 209699_x_at & AKR1C2 & $\begin{array}{l}\text { aldo-keto reductase family } 1 \text {, member } \mathrm{C} 2 \text { (dihydrodiol dehydrogenase } 2 \text {; bile } \\
\text { acid binding protein; } 3 \text {-alpha hydroxysteroid dehydrogenase, type III) }\end{array}$ \\
\hline 212224_at & ALDH1A1 & aldehyde dehydrogenase 1 family, member A1 \\
\hline 204446_s_at & ALOX5 & arachidonate 5-lipoxygenase \\
\hline 205216_s_at & $\mathrm{APOH}$ & apolipoprotein H (beta-2-glycoprotein I) \\
\hline 39248_at & AQP3 & aquaporin 3 (Gill blood group) \\
\hline 218501_at & ARHGEF3 & Rho guanine nucleotide exchange factor (GEF) 3 \\
\hline 219087_at & ASPN & Aspirin \\
\hline 201242_s_at & ATP1B1 & ATPase, $\mathrm{Na}+/ \mathrm{K}+$ transporting, beta 1 polypeptide \\
\hline 200921_s_at & BTG1 & B-cell translocation gene 1 , anti-proliferative \\
\hline 228067_at & C2orf55 & chromosome 2 open reading frame 55 \\
\hline 206488_s_at & CD36 & CD36 molecule (thrombospondin receptor) \\
\hline 208783_s_at & CD46 & CD46 molecule, complement regulatory protein \\
\hline 1553970_s_at & CEL & carboxyl ester lipase (bile salt-stimulated lipase) \\
\hline 203854_at & CFI & complement factor I \\
\hline 205043_at & CFTR & $\begin{array}{l}\text { cystic fibrosis transmembrane conductance regulator (ATP-binding cassette } \\
\text { sub-family C, member 7) }\end{array}$ \\
\hline 204260_at & $\mathrm{CHGB}$ & chromogranin B (secretogranin 1) \\
\hline 221188_s_at & CIDEB & cell death-inducing DFFA-like effector b \\
\hline 203953_s_at & CLDN3 & claudin 3 \\
\hline 221042_s_at & CLMN & calmin (calponin-like, transmembrane) \\
\hline 1567081_x_at & CLN6 & ceroid-lipofuscinosis, neuronal 6, late infantile, variant \\
\hline 208791_at & CLU & Clusterin \\
\hline 229831_at & CNTN3 & contactin 3 (plasmacytoma associated) \\
\hline 205615_at & CPA1 & carboxypeptidase A1 (pancreatic) \\
\hline 206212_at & CPA2 & carboxypeptidase A2 (pancreatic) \\
\hline 205509_at & $\mathrm{CPB} 1$ & carboxypeptidase B1 (tissue) \\
\hline 201117_s_at & $\mathrm{CPE}$ & carboxypeptidase E \\
\hline 224829_at & CPEB4 & cytoplasmic polyadenylation element binding protein 4 \\
\hline 204920_at & CPS1 & carbamoyl-phosphate synthetase 1 , mitochondrial \\
\hline 201990_s_at & CREBL2 & cAMP responsive element binding protein-like 2 \\
\hline 205971_s_at & CTRB1 /// CTRB2 & chymotrypsinogen B1 /// chymotrypsinogen B2 \\
\hline 214411_x_at & CTRB2 & chymotrypsinogen B2 \\
\hline 209774_x_at & CXCL2 & chemokine (C-X-C motif) ligand 2 \\
\hline 205765_at & CYP3A5 & cytochrome P450, family 3 , subfamily A, polypeptide 5 \\
\hline 228391_at & CYP4V2 & cytochrome P450, family 4 , subfamily V, polypeptide 2 \\
\hline 228739_at & CYS1 & cystin 1 \\
\hline 222925_at & DCDC2 & doublecortin domain containing 2 \\
\hline
\end{tabular}


Table 3: Continued.

\begin{tabular}{|c|c|c|}
\hline Probe set ID & Gene symbol & Gene title \\
\hline 205311_at & DDC & dopa decarboxylase (aromatic L-amino acid decarboxylase) \\
\hline 210397_at & DEFB1 & defensin, beta 1 \\
\hline 221081_s_at & DENND2D & DENN/MADD domain containing 2D \\
\hline 214787_at & DENND4A & DENN/MADD domain containing 4A \\
\hline 205684_S_at & DENND4C & DENN/MADD domain containing 4C \\
\hline 214079_at & DHRS2 & dehydrogenase/reductase (SDR family) member 2 \\
\hline 222850_s_at & DNAJB14 & DnaJ (Hsp40) homolog, subfamily B, member 14 \\
\hline 225415_at & DTX3L & deltex 3-like (Drosophila) \\
\hline 225645_at & EHF & Ets homologous factor \\
\hline 210080_x_at & ELA3A & elastase $3 \mathrm{~A}$, pancreatic \\
\hline 201510_at & ELF3 & E74-like factor 3 (ets domain transcription factor, epithelial-specific) \\
\hline 206191_at & ENTPD3 & ectonucleoside triphosphate diphosphohydrolase 3 \\
\hline 220012_at & ERO1LB & ERO1-like beta (S. cerevisiae) \\
\hline 210103_s_at & FOXA2 & forkhead box A2 \\
\hline 235201_at & FOXP2 & forkhead box P2 \\
\hline 226847_at & FST & Follistatin \\
\hline 205674_x_at & FXYD2 & FXYD domain containing ion transport regulator 2 \\
\hline 205890_s_at & GABBR1 /// UBD & gamma-aminobutyric acid (GABA) B receptor, $1 / / /$ ubiquitin D \\
\hline 205848_at & GAS2 & growth arrest-specific 2 \\
\hline 216733_s_at & GATM & glycine amidinotransferase (L-arginine:glycine amidinotransferase) \\
\hline 204965_at & GC & group-specific component (vitamin D binding protein) \\
\hline 219508_at & GCNT3 & glucosaminyl ( $\mathrm{N}$-acetyl) transferase 3 , mucin type \\
\hline 225853_at & GNPNAT1 & glucosamine-phosphate $\mathrm{N}$-acetyltransferase 1 \\
\hline 212950_at & GPR116 & G protein-coupled receptor 116 \\
\hline 212070_at & GPR56 & G protein-coupled receptor 56 \\
\hline 203924_at & GSTA1 & glutathione S-transferase A1 \\
\hline 221942_s_at & GUCY1A3 & guanylate cyclase 1 , soluble, alpha 3 \\
\hline 228697_at & HINT3 & histidine triad nucleotide binding protein 3 \\
\hline 209558_s_at & HIP1R & huntingtin interacting protein 1 related \\
\hline 207062_at & IAPP & islet amyloid polypeptide \\
\hline 213620_s_at & ICAM2 & intercellular adhesion molecule 2 \\
\hline 203828_s_at & IL32 & interleukin 32 \\
\hline 205945_at & IL6R & interleukin 6 receptor \\
\hline 206598_at & INS & Insulin \\
\hline 226535_at & ITGB6 & integrin, beta 6 \\
\hline 226189_at & ITGB8 & integrin, beta 8 \\
\hline 210078_s_at & KCNAB1 & potassium voltage-gated channel, shaker-related subfamily, beta member 1 \\
\hline 219564_at & KCNJ16 & potassium inwardly-rectifying channel, subfamily J, member 16 \\
\hline 205303_at & KCNJ8 & potassium inwardly-rectifying channel, subfamily J, member 8 \\
\hline 212531_at & LCN2 & lipocalin 2 \\
\hline 235970_at & LCORL & ligand dependent nuclear receptor corepressor-like \\
\hline 1554006_a_at & LLGL2 & lethal giant larvae homolog 2 (Drosophila) \\
\hline 225996_at & LONRF2 & LON peptidase $\mathrm{N}$-terminal domain and ring finger 2 \\
\hline 242931_at & LONRF3 & LON peptidase $\mathrm{N}$-terminal domain and ring finger 3 \\
\hline 226748_at & LYSMD2 & LysM, putative peptidoglycan-binding, domain containing 2 \\
\hline
\end{tabular}


Table 3: Continued.

\begin{tabular}{|c|c|c|}
\hline Probe set ID & Gene symbol & Gene title \\
\hline 213975_s_at & LYZ & lysozyme (renal amyloidosis) \\
\hline 222670_s_at & MAFB & v-maf musculoaponeurotic fibrosarcoma oncogene homolog B (avian) \\
\hline 223577_x_at & MALAT1 & metastasis associated lung adenocarcinoma transcript 1 (non-protein coding) \\
\hline 220945_x_at & MANSC1 & MANSC domain containing 1 \\
\hline 204388_s_at & MAOA & monoamine oxidase A \\
\hline 235077_at & MEG3 & maternally expressed 3 \\
\hline 229254_at & MFSD4 & major facilitator superfamily domain containing 4 \\
\hline 219797_at & MGAT4A & $\begin{array}{l}\text { mannosyl (alpha-1,3-)-glycoprotein beta-1,4-N-acetylglucosaminyltransferase, } \\
\text { isozyme A }\end{array}$ \\
\hline 204259_at & MMP7 & matrix metallopeptidase 7 (matrilysin, uterine) \\
\hline 227747_at & MPZL3 & myelin protein zero-like 3 \\
\hline 204438_at & $\mathrm{MRC1} / / / \mathrm{MRC} 1 \mathrm{~L} 1$ & mannose receptor, $\mathrm{C}$ type $1 / / /$ mannose receptor, $\mathrm{C}$ type 1 -like 1 \\
\hline 203037_s_at & MTSS1 & metastasis suppressor 1 \\
\hline 212093_s_at & MTUS1 & mitochondrial tumor suppressor 1 \\
\hline 213693_s_at & MUC1 & mucin 1 , cell surface associated \\
\hline 213375_s_at & N4BP2L1 & NEDD4 binding protein 2-like 1 \\
\hline 220184_at & NANOG & Nanog homeobox \\
\hline 209107_x_at & NCOA1 & nuclear receptor coactivator 1 \\
\hline 1556057_s_at & NEUROD1 & neurogenic differentiation 1 \\
\hline 206915_at & NKX2-2 & NK2 homeobox 2 \\
\hline 225911_at & NPNT & Nephronectin \\
\hline 205259_at & NR3C2 & nuclear receptor subfamily 3 , group C, member 2 \\
\hline 212768_s_at & OLFM4 & olfactomedin 4 \\
\hline 203845_at & PCAF & p300/CBP-associated factor \\
\hline 240317_at & PCDHB4 & protocadherin beta 4 \\
\hline 212593_s_at & PDCD4 & programmed cell death 4 (neoplastic transformation inhibitor) \\
\hline 213228_at & PDE8B & phosphodiesterase 8B \\
\hline 225207_at & PDK4 & pyruvate dehydrogenase kinase, isozyme 4 \\
\hline 205380_at & PDZK1 & PDZ domain containing 1 \\
\hline 1553589_a_at & PDZK1IP1 & PDZK1 interacting protein 1 \\
\hline 226459_at & PIK3AP1 & phosphoinositide-3-kinase adaptor protein 1 \\
\hline 220954_s_at & PILRB & paired immunoglobulin-like type 2 receptor beta \\
\hline 219584_at & PLA1A & phospholipase A1 member A \\
\hline 206311_s_at & PLA2G1B & phospholipase A2, group IB (pancreas) \\
\hline 221529_s_at & PLVAP & plasmalemma vesicle associated protein \\
\hline 205912_at & PNLIP & pancreatic lipase \\
\hline 211766_s_at & PNLIPRP2 & pancreatic lipase-related protein 2 \\
\hline 208286_x_at & POU5F1(Oct4) & $\begin{array}{l}\text { POU class } 5 \text { homeobox } 1 / / / \text { POU class } 5 \text { homeobox } 1 \mathrm{~B} / / / \text { POU class } 5 \\
\text { homeobox } 1 \text { pseudogene } 3 / / / \text { POU class } 5 \text { homeobox } 1 \text { pseudogene } 4\end{array}$ \\
\hline 228469_at & PPID & Peptidylprolyl isomerase D (cyclophilin D) \\
\hline 210670_at & PPY & pancreatic polypeptide \\
\hline 242482_at & PRKAR1A & $\begin{array}{l}\text { protein kinase, cAMP-dependent, regulatory, type I, alpha (tissue specific } \\
\text { extinguisher 1) }\end{array}$ \\
\hline 227629_at & PRLR & Prolactin receptor \\
\hline 228656_at & PROX1 & prospero homeobox 1 \\
\hline 205869_at & PRSS1 & protease, serine, 1 (trypsin 1 ) \\
\hline 205402_x_at & PRSS2 & protease, serine, 2 (trypsin 2$)$ \\
\hline
\end{tabular}


Table 3: Continued.

\begin{tabular}{|c|c|c|}
\hline Probe set ID & Gene symbol & Gene title \\
\hline 213421_x_at & PRSS3 & protease, serine, 3 \\
\hline 203317_at & PSD4 & pleckstrin and Sec7 domain containing 4 \\
\hline 203029_s_at & PTPRN2 & protein tyrosine phosphatase, receptor type, $\mathrm{N}$ polypeptide 2 \\
\hline $219562 \_$at & RAB26 & RAB26, member RAS oncogene family \\
\hline 226436_at & RASSF4 & Ras association (RalGDS/AF-6) domain family member 4 \\
\hline 223322_at & RASSF5 & Ras association (RalGDS/AF-6) domain family member 5 \\
\hline 235638_at & RASSF6 & Ras association (RalGDS/AF-6) domain family member 6 \\
\hline 204364_s_at & REEP1 & receptor accessory protein 1 \\
\hline 209752_at & REG1A & $\begin{array}{l}\text { regenerating islet-derived } 1 \text { alpha (pancreatic stone protein, pancreatic thread } \\
\text { protein) }\end{array}$ \\
\hline 205886_at & REG1B & $\begin{array}{l}\text { regenerating islet-derived } 1 \text { beta (pancreatic stone protein, pancreatic thread } \\
\text { protein) }\end{array}$ \\
\hline 205815_at & REG3A & regenerating islet-derived 3 alpha \\
\hline 1554003_at & RGNEF & Rho-guanine nucleotide exchange factor \\
\hline 219263_at & RNF128 & ring finger protein 128 \\
\hline 221614_s_at & RPH3AL & rabphilin 3A-like (without C2 domains) \\
\hline 213939_s_at & RUFY3 & RUN and FYVE domain containing 3 \\
\hline 210592_s_at & SAT1 & spermidine/spermine N1-acetyltransferase 1 \\
\hline 203408_s_at & SATB1 & SATB homeobox 1 \\
\hline 204035_at & SCG2 & secretogranin II (chromogranin C) \\
\hline 205697_at & SCGN & secretagogin, EF-hand calcium binding protein \\
\hline 229620_at & SEPP1 & Selenoprotein P, plasma, 1 \\
\hline 202833_s_at & SERPINA1 & $\begin{array}{l}\text { serpin peptidase inhibitor, clade A (alpha-1 antiproteinase, antitrypsin), } \\
\text { member } 1\end{array}$ \\
\hline 202376_at & SERPINA3 & $\begin{array}{l}\text { serpin peptidase inhibitor, clade A (alpha-1 antiproteinase, antitrypsin), } \\
\text { member } 3\end{array}$ \\
\hline 209443_at & SERPINA5 & $\begin{array}{l}\text { serpin peptidase inhibitor, clade A (alpha-1 antiproteinase, antitrypsin), } \\
\text { member } 5\end{array}$ \\
\hline 213572_s_at & SERPINB1 & serpin peptidase inhibitor, clade B (ovalbumin), member 1 \\
\hline 227627_at & SGK3 & serum/glucocorticoid regulated kinase family, member 3 \\
\hline 219256_s_at & SH3TC1 & SH3 domain and tetratricopeptide repeats 1 \\
\hline 204019_s_at & SH3YL1 & SH3 domain containing, Ysc84-like 1 (S. cerevisiae) \\
\hline 213464_at & $\mathrm{SHC} 2$ & SHC (Src homology 2 domain containing) transforming protein 2 \\
\hline 205799_s_at & SLC3A1 & $\begin{array}{l}\text { solute carrier family } 3 \text { (cystine, dibasic and neutral amino acid transporters, } \\
\text { activator of cystine, dibasic and neutral amino acid transport), member } 1\end{array}$ \\
\hline 223044_at & SLC40A1 & solute carrier family 40 (iron-regulated transporter), member 1 \\
\hline 228221_at & SLC44A3 & solute carrier family 44 , member 3 \\
\hline 213139_at & SNAI2(Slug) & snail homolog 2 (Drosophila) \\
\hline 1560228_at & SNAI3(Snail) & snail homolog 3 (Drosophila) \\
\hline 213721_at & SOX2 & SRY (sex determining region Y)-box 2 \\
\hline 200795_at & SPARCL1 & SPARC-like 1 (mast9, hevin) \\
\hline 206239_s_at & SPINK1 & serine peptidase inhibitor, Kazal type 1 \\
\hline 213921_at & SST & somatostatin \\
\hline 216905_s_at & ST14 & suppression of tumorigenicity 14 (colon carcinoma) \\
\hline 230285_at & SVIP & small VCP/p97-interacting protein \\
\hline 227134_at & SYTL1 & synaptotagmin-like 1 \\
\hline 202286_s_at & TACSTD2 & tumor-associated calcium signal transducer 2 \\
\hline 205513_at & TCN1 & transcobalamin I (vitamin B12 binding protein, R binder family) \\
\hline 203887_s_at & THBD & thrombomodulin \\
\hline 209937_at & TM4SF4 & transmembrane $4 \mathrm{~L}$ six family member 4 \\
\hline 226403_at & TMC4 & transmembrane channel-like 4 \\
\hline
\end{tabular}


Table 3: Continued.

\begin{tabular}{lcl}
\hline Probe set ID & Gene symbol & Gene title \\
\hline 223503_at & TMEM163 & transmembrane protein 163 \\
218345_at & TMEM176A & transmembrane protein 176A \\
220532_s_at & TMEM176B & transmembrane protein 176B \\
200847_s_at & TMEM66 & transmembrane protein 66 \\
202687_s_at & TNFSF10 & tumor necrosis factor (ligand) superfamily, member 10 \\
203824_at & TSPAN8 & tetraspanin 8 \\
229169_at & TTC18 & tetratricopeptide repeat domain 18 \\
209660_at & TTR & transthyretin (prealbumin, amyloidosis type I) \\
231008_at & UNC5CL & Unc-5 homolog C (C. elegans)-like \\
226344_at & ZMAT1 & zinc finger, matrin type 1 \\
206059_at & ZNF91 & zinc finger protein 91 \\
\hline
\end{tabular}

\begin{tabular}{|c|c|c|c|c|}
\hline $\begin{array}{c}\text { Lung metastasis } \\
\text { (cell no. }\end{array}$ & ALDH1 $^{-}$ & ALDH1 $^{-} /$vector & ALDH1 ${ }^{-} /$Bmil & ALDH1 $^{+}$ \\
\hline $5 \times 10^{4}$ & $0 / 3$ & $0 / 3$ & $1 / 3$ & $3 / 3$ \\
\hline $5 \times 10^{5}$ & $0 / 3$ & $0 / 3$ & $3 / 3$ & $3 / 3$ \\
\hline
\end{tabular}

(a)

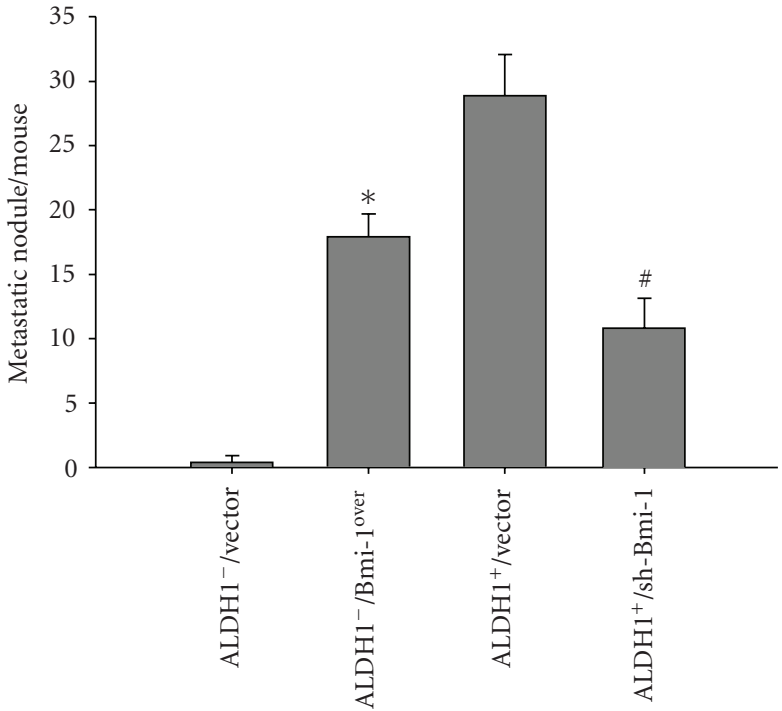

(b)

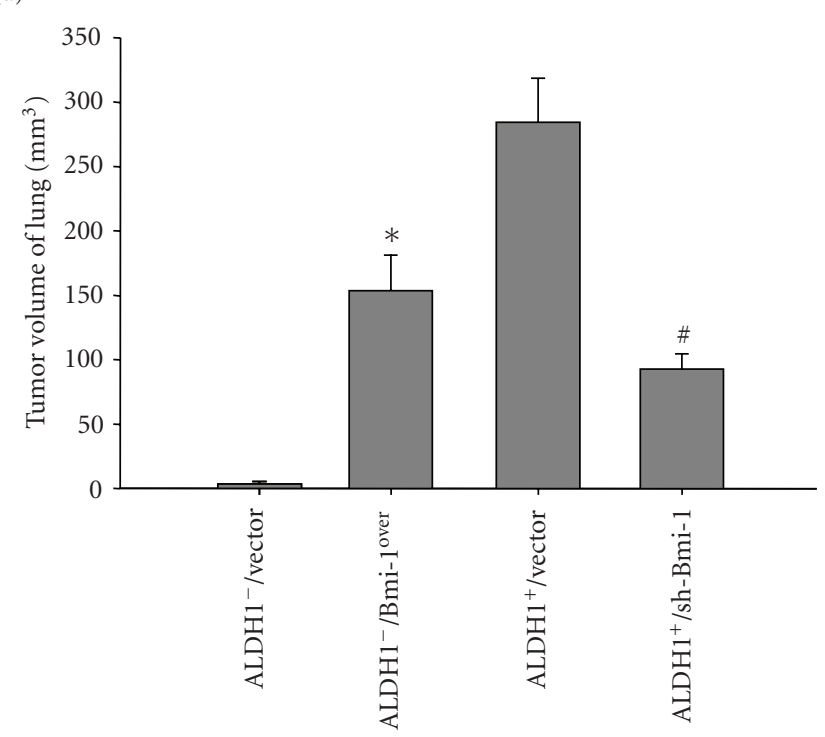

(c)

FIGURE 5: Elimination of metastatic activity in HNSCC-ALDH1 ${ }^{+}$cells treated with shBmi-1. (a) Summary of the in vivo metastasis ability of different numbers of HNSCC-ALDH1 ${ }^{+}$, sh-Bmi-1 treated HNSCC-ALDH1 ${ }^{+}$, HNSCC- ALDH1 ${ }^{-}$, or Bmi-1-overexpressing HNSCCALDH1 ${ }^{-}$cells examined by xenotransplantation analysis. (b) The average numbers of metastatic foci (left panel) and total weight (right panel) in the lungs of mice treated with either HNSCC-ALDH1 $1^{+}$, sh-Bmi-1 treated HNSCC-ALDH1 ${ }^{+}$, HNSCC- ALDH1- ${ }^{-}$or Bmi-1-overexpressing HNSCC-ALDH1 ${ }^{-}$cells are shown. $\left({ }^{*} P<.05: \mathrm{ALDH}^{-}\right.$versus Bmi-1-overexpressing ALDH1 ${ }^{-} ;{ }^{\#} P<.05: \mathrm{ALDH}^{+}$versus shBmi-1 treated HNSCC-ALDH1 $1^{+}$.

assays, Chen et al. confirmed that ALDH1+-lineage cells underwent epithelial-mesenchymal transition (EMT) and endogenously co-expressed Snail [13]. In the current study, our data demonstrated that HNSCC-ALDH1 ${ }^{+}$cells had high levels of Bmi-1, at both the mRNA and protein levels (Figure 2). Using a lentiviral vector expressing shRNA targeting
Bmi-1, we observed that the level of ALDH1 expression and tumorigenic properties of HNSCC-ALDH1 ${ }^{+}$could be downregulated by knockdown of Bmi-1 (Figure 2). Importantly, overexpression of Bmi-1 could turn HNSCC-ALDH1 ${ }^{-}$into cancer stem cell-like HNSCC-ALDH1 ${ }^{+}$cells (Figure 3 ). Consistent with these findings, the immunohistochemical 


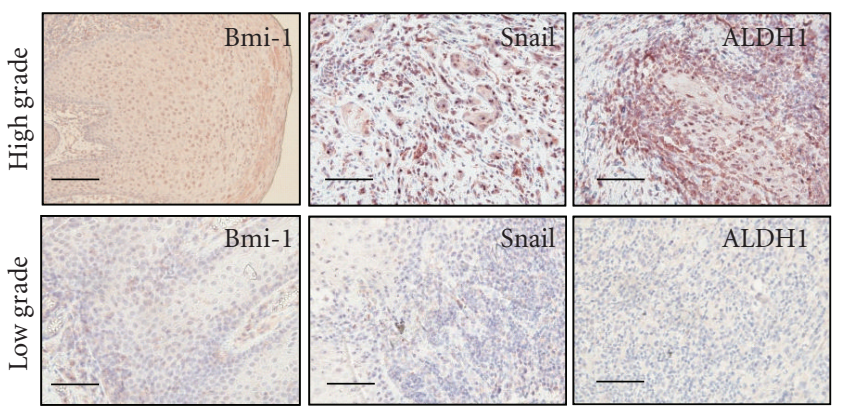

(a)

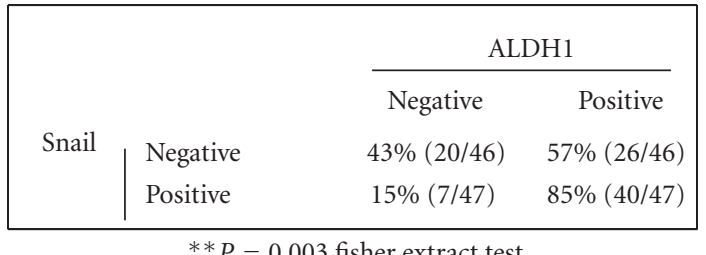

** $P=0.003$ fisher extract test

(c)

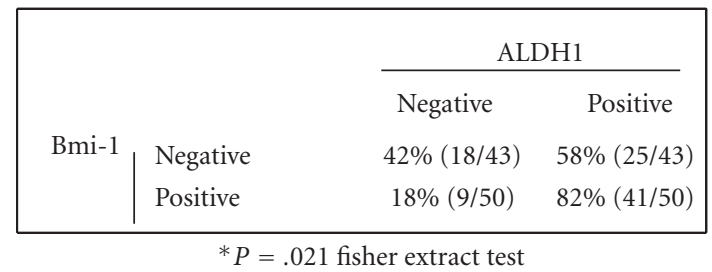

(b)

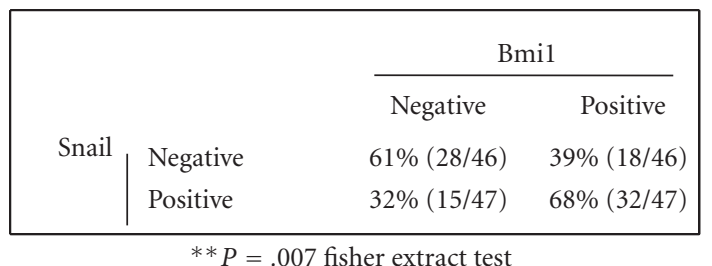

(d)

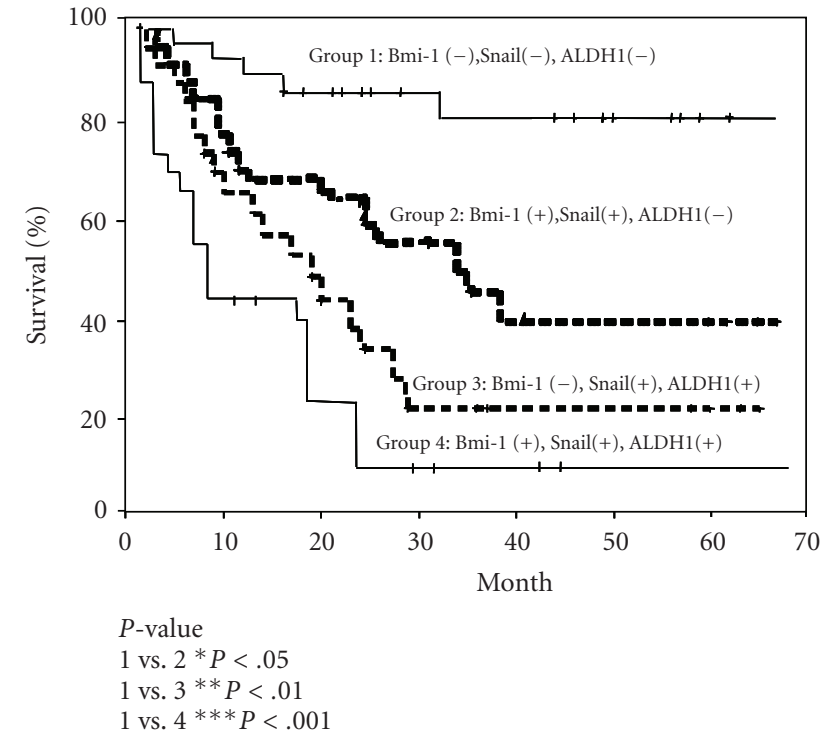

(e)

Figure 6: Coexpression of Bmi-1, Snail, and ALDH1 in HNSCC patient specimen and prediction of survival of the HNSCC patients. (a) Representative pictures of triple positive (upper panel) and triple negative (lower panel) HNSCC cases. Coexpression of Bmi-1 and ALDH1 (b), Bmi-1 and Snail (c) or Snail and Bmi-1 (d) of 93 HNSCC patient samples were examined immunohistochemically. (e) Kaplan-Meier analysis of overall survival of HNSCC patients according to expression of ALDH1 (+) Bmi-1 (+) Snail (+), ALDH1 (+) Bmi-1 (+) Snail (-), ALDH1 (-) Bmi-1 (+) Snail (+) or ALDH1 (-) Bmi-1 (-) Snail $(-) .\left(^{*}, P<.05 ; * *, P<.01\right.$; $\left.^{* *}, P<.001\right)$.

survey of 93 HNSCC patient tissues showed a positive correlation between expression of Bmi-1, Snail, or ALDH1 and tumor stage (Figure 6). Similar results were noted in other malignancies [40]. Kaplan-Meier analysis demonstrated that patients expressing Bmi-1, Snail, and ALDH1 were predicted to have the worst survival prognosis of HNSCC patients (Figure 6(e)). However, a recent study showed a significant correlation between negative Bmi-1 protein expression and the recurrence of tongue cancer. Their results showed Snail and c-myc expression did not correlate with prognosis [41]. The divergence from our results may be due to the different pathophysiology of HNSCC. Most HNSCC patients in Taiwan consume alcohol, chew betel quid and smoke cigarettes. Tongue cancer patients, especially female tongue cancer patients, usually do not have these habits [3]. The close relationship between tongue cancer and human papillomavirus has been explored by many researchers [ $42-$ 45]. The correlation between cancer stem cells and the virus infection remains to be discovered.

The prognosis of HNSCC patients with distant metastases in the lung, liver, and bone is very poor $[3,46]$. In this study, we found that Bmi-1 can regulate Snail and ALDH1; 
change the EMT-related genotypes of the ALDH1 ${ }^{-}$cells; and modulate distant lung metastases (Figure 5). Distant metastases have been reported to be associated with Bmi-1 expression in breast cancer [47-49], melanoma [50], gastric cancer [51], and colon cancer [30]. Microarray analysis revealed that eleven gene signatures, which were correlated to the Bmi-1-driven pathway, were closely related to distant lung metastases [40]. Bmi-1 is the target gene of SALL4 in human hematopoietic as well as leukemic cells and is downregulated if SALL4 is knocked down by the siRNA in the HL60 leukemia cell line $[52,53]$. Recently, researchers employed microRNA profiling to gain insight into the role of Bmi-1 in regulating EMT. Overexpression of miR-200c decreased Bmi1 expression in breast cancer stem cells (BCSCs) and inhibited the formation of mammary ducts as well as tumors by normal mammary stem cells and BCSCs [54]. Bhattacharya et al. found that miR-15a and miR-16 directly targeted the Bmi-1 $3^{\prime}$ untranslated region and correlated with Bmi-1 protein levels in ovarian cancer patients and cell lines [55]. Further research effort is needed in this area. Together, our research shows that the Bmi-1 signaling pathways play a major role in the maintenance of stemness and the metastatic ability of HNSCC-CSC by regulating of Snail expression. Additionally, we demonstrate coexpression of Bmi-1, Snail, and ALDH1 in HNSCC patients was positively correlated with tumor grade and the worst prognosis.

\section{Acknowledgments}

This study was supported by research Grants from the National Science Council (NSC-97-3111-B-075-001MY3/98-2314-B-075-008-MY3), the Taipei Veterans General Hospital (V97B1-006/E1-008/F-001/F-010), the National Yang-Ming University (Ministry of Education, Aim for the Top University Plan), the Chung Shan Medical University Hospital (CSH-2010-C-025), the Technology Development Program for Academia (98-EC-17-A-19-S2-0107), and Department of Industrial Technology, Ministry of Economic Affairs, Taiwan.

\section{References}

[1] R. I. Haddad and D. M. Shin, "Recent advances in head and neck cancer," The New England Journal of Medicine, vol. 359, no. 11, pp. 1143-1096, 2008.

[2] Y.-J. Chen, J. T.-C. Chang, C.-T. Liao et al., "Head and neck cancer in the betel quid chewing area: recent advances in molecular carcinogenesis," Cancer Science, vol. 99, no. 8, pp. 1507-1514, 2008.

[3] W.-L. Lo, S.-Y. Kao, L.-Y. Chi, Y.-K. Wong, and R. C.-S. Chang, "Outcomes of oral squamous cell carcinoma in Taiwan after surgical therapy: factors affecting survival," Journal of Oral and Maxillofacial Surgery, vol. 61, no. 7, pp. 751-758, 2003.

[4] J. P. Their, "Epithelial-mesenchymal transitions in tumor progression," Nature Reviews Cancer, vol. 2, no. 6, pp. 442 454, 2002.

[5] J. P. Thiery and J. P. Sleeman, "Complex networks orchestrate epithelial-mesenchymal transitions," Nature Reviews Molecular Cell Biology, vol. 7, no. 2, pp. 131-142, 2006.
[6] S. A. Mani, W. Guo, M.-J. Liao et al., "The epithelialmesenchymal transition generates cells with properties of stem cells," Cell, vol. 133, no. 4, pp. 704-715, 2008.

[7] E. Batlle, E. Sancho, C. Franci et al., "The transcription factor Snail is a repressor of E-cadherin gene expression in epithelial tumour cells," Nature Cell Biology, vol. 2, no. 2, pp. 84-89, 2000.

[8] B. P. Zhou, J. Deng, W. Xia et al., "Dual regulation of Snail by GSK- $3 \beta$-mediated phosphorylation in control of epithelialmesenchymal transition," Nature Cell Biology, vol. 6, no. 10, pp. 931-940, 2004.

[9] A. Yoshida, "Molecular genetics of human aldehyde dehydrogenase," Pharmacogenetics, vol. 2, no. 4, pp. 139-147, 1992.

[10] M. R. Clay, M. Tabor, J. H. Owen et al., "Single-marker identification of head and neck squamous cell carcinoma cancer stem cells with aldehyde dehydrogenase," Head Neck, vol. 32, no. 9, pp. 1195-1201, 2010.

[11] Z. G. Chen, "The cancer stem cell concept in progression of head and neck cancer," Journal of Oncology, vol. 2009, Article ID 894064, 8 pages, 2009.

[12] C. M. Sterz, C. Kulle, B. Dakic et al., "A basal-cell-like compartment in head and neck squamous cell carcinomas represents the invasive front of the tumor and is expressing MMP-9," Oral Oncology, vol. 46, no. 2, pp. 116-122, 2010.

[13] Y.-C. Chen, Y.-W. Chen, H.-S. Hsu et al., "Aldehyde dehydrogenase 1 is a putative marker for cancer stem cells in head and neck squamous cancer," Biochemical and Biophysical Research Communications, vol. 385, no. 3, pp. 307-313, 2009.

[14] V. Pirrotta, "Polycombing the genome: PcG, trxG and chromatin silencing," Cell, vol. 93, no. 3, pp. 333-336, 1998.

[15] A. V. Molofsky, R. Pardal, T. Iwashita, I.-K. Park, M. F. Clarke, and S. J. Morrison, "Bmi-1 dependence distinguishes neural stem cell self-renewal from progenitor proliferation," Nature, vol. 425, no. 6961, pp. 962-967, 2003.

[16] I.-K. Park, D. Qian, M. Kiel et al., "Bmi-1 is required for maintenance of adult self-renewing haematopoietic stem cells," Nature, vol. 423, no. 6937, pp. 302-305, 2003.

[17] E. Sangiorgi and M. R. Capecchi, "Bmil is expressed in vivo in intestinal stem cells," Nature Genetics, vol. 40, no. 7, pp. 915920, 2008.

[18] Y. Haupt, W. S. Alexander, G. Barri, S. P. Klinken, and J. M. Adams, "Novel zinc finger gene implicated as myc collaborator by retrovirally accelerated lymphomagenesis in $\mathrm{E}$ $\mu$-myc transgenic mice," Cell, vol. 65, no. 5, pp. 753-763, 1991.

[19] J. J. L. Jacobs, B. Scheijen, J.-W. Voncken, K. Kieboom, A. Berns, and M. Van Lohuizen, "Bmi-1 collaborates with cMyc in tumorigenesis by inhibiting c-Myc-induced apoptosis via INK4a/ARF," Genes and Development, vol. 13, no. 20, pp. 2678-2690, 1999.

[20] Z.-K. Qin, J.-A. Yang, Y.-L. Ye et al., "Expression of Bmi-1 is a prognostic marker in bladder cancer," BMC Cancer, vol. 9, article 61, 2009.

[21] C. S. Cooper and C. S. Foster, "Concepts of epigenetics in prostate cancer development," British Journal of Cancer, vol. 100, no. 2, pp. 240-245, 2009.

[22] V. Häyry, O. Tynninen, H. K. Haapasalo et al., "Stem cell protein BMI-1 is an independent marker for poor prognosis in oligodendroglial tumours," Neuropathology and Applied Neurobiology, vol. 34, no. 5, pp. 555-563, 2008.

[23] R. Tirabosco, G. De Maglio, M. Skrap, G. Falconieri, and S. Pizzolitto, "Expression of the polycomb-group protein BMI1 and correlation with p16 in astrocytomas. An immunohistochemical study on 80 cases," Pathology Research and Practice, vol. 204, no. 9, pp. 625-631, 2008. 
[24] J. B. Arnes, K. Collett, and L. A. Akslen, "Independent prognostic value of the basal-like phenotype of breast cancer and associations with EGFR and candidate stem cell marker BMI-1," Histopathology, vol. 52, no. 3, pp. 370-380, 2008.

[25] W. Song, K. Tao, H. Li et al., "Bmi-1 is related to proliferation, survival and poor prognosis in pancreatic cancer," Cancer Science, vol. 101, no. 7, pp. 1754-1760, 2010.

[26] K. Vrzalikova, J. Skarda, J. Ehrmann et al., "Prognostic value of Bmi-1 oncoprotein expression in NSCLC patients: a tissue microarray study," Journal of Cancer Research and Clinical Oncology, vol. 134, no. 9, pp. 1037-1042, 2008.

[27] M. Brunner, D. Thurnher, J. Pammer et al., "Expression of VEGF-A/C, VEGF-R2, PDGF- $\alpha / \beta$, c-kit, EGFR, Her-2/Neu, Mcl-1 and Bmi-1 in Merkel cell carcinoma," Modern Pathology, vol. 21, no. 7, pp. 876-884, 2008.

[28] P. Zhang, Y. Zhang, L. Mao, Z. Zhang, and W. Chen, "Side population in oral squamous cell carcinoma possesses tumor stem cell phenotypes," Cancer Letters, vol. 277, no. 2, pp. 227234, 2009.

[29] Y. Jiang, B. Su, X. Meng et al., "Effect of siRNA-mediated silencing of Bmi-1 gene expression on HeLa cells," Cancer Science, vol. 101, no. 2, pp. 379-386, 2010.

[30] D. W. Li, H. M. Tang, J. W. Fan et al., "Expression level of Bmi1 oncoprotein is associated with progression and prognosis in colon cancer," Journal of Cancer Research and Clinical Oncology, vol. 136, no. 7, pp. 997-1006, 2010.

[31] L. B. Song, J. Li, W. T. Liao et al., "The polycomb group protein Bmi-1 represses the tumor suppressor PTEN and induces epithelial-mesenchymal transition in human nasopharyngeal epithelial cells," The Journal of Clinical Investigation, vol. 119, no. 12, pp. 3626-3636, 2009.

[32] C. C. Yu, G. Y. Chiou, Y. Y. Lee et al., "Medulloblastomaderived tumor stem-like cells acquired resistance to TRAILinduced apoptosis and radiosensitivity," Child's Nervous System, vol. 26, no. 7, pp. 897-904, 2010.

[33] S.-H. Chiou, C.-L. Kao, Y.-W. Chen et al., "Identification of CD133-positive radioresistant cells in atypical teratoid/rhabdoid tumor," PLoS ONE, vol. 3, no. 5, article e2090, 2008.

[34] S.-H. Chiou, C.-C. Yu, C.-Y. Huang et al., "Positive correlations of Oct-4 and Nanog in oral cancer stem-like cells and high-grade oral squamous cell carcinoma," Clinical Cancer Research, vol. 14, no. 13, pp. 4085-4095, 2008.

[35] Y. C. Chen, C. J. Chang, H. S. Hsu et al., "Inhibition of tumorigenicity and enhancement of radiochemosensitivity in head and neck squamous cell cancer-derived ALDH1-positive cells by knockdown of Bmi-1," Oral Oncology, vol. 46, no. 3, pp. 158-165, 2010.

[36] M. Baumann, M. Krause, and R. Hill, "Exploring the role of cancer stem cells in radioresistance," Nature Reviews Cancer, vol. 8, no. 7, pp. 545-554, 2008.

[37] M.-H. Yang, M.-Z. Wu, S.-H. Chiou et al., "Direct regulation of TWIST by HIF- $1 \alpha$ promotes metastasis," Nature Cell Biology, vol. 10, no. 3, pp. 295-305, 2008.

[38] Y. C. Chen, C. J. Chang, H. S. Hsu et al., "Inhibition of tumorigenicity and enhancement of radiochemosensitivity in head and neck squamous cell cancer-derived ALDH1-positive cells by knockdown of Bmi-1," Oral Oncology, vol. 46, no. 3, pp. 158-165, 2010.

[39] M. E. Prince, R. Sivanandan, A. Kaczorowski et al., "Identification of a subpopulation of cells with cancer stem cell properties in head and neck squamous cell carcinoma," Proceedings of the National Academy of Sciences of the United States of America, vol. 104, no. 3, pp. 973-978, 2007.
[40] G. V. Glinsky, O. Berezovska, and A. B. Glinskii, "Microarray analysis identifies a death-from-cancer signature predicting therapy failure in patients with multiple types of cancer," Journal of Clinical Investigation, vol. 115, no. 6, pp. 1503-1521, 2005.

[41] V. Häyry, L. K. Mäkinen, T. Atula et al., "Bmi-1 expression predicts prognosis in squamous cell carcinoma of the tongue," British Journal of Cancer, vol. 102, no. 5, pp. 892-897, 2010.

[42] P. Attner, J. Du, A. Näsman et al., "The role of human papillomavirus in the increased incidence of base of tongue cancer," International Journal of Cancer, vol. 126, no. 12, pp. 2879-2884, 2010.

[43] A. Salem, "Dismissing links between HPV and aggressive tongue cancer in young patients," Annals of Oncology, vol. 21, no. 1, pp. 13-17, 2010.

[44] X.-H. Liang, J. Lewis, R. Foote, D. Smith, and D. Kademani, "Prevalence and significance of human papillomavirus in oral tongue cancer: the Mayo Clinic experience," Journal of Oral and Maxillofacial Surgery, vol. 66, no. 9, pp. 1875-1880, 2008.

[45] L. Dahlgren, H. Dahlstrand, D. Lindquist et al., "Human papillomavirus is more common in base of tongue than in mobile tongue cancer and is a favorable prognostic factor in base of tongue cancer patients," International Journal of Cancer, vol. 112, no. 6, pp. 1015-1019, 2004.

[46] D. Sano and J. N. Myers, "Metastasis of squamous cell carcinoma of the oral tongue," Cancer and Metastasis Reviews, vol. 26, no. 3-4, pp. 645-662, 2007.

[47] J. H. Kim, S. Y. Yoon, S.-H. Jeong et al., "Overexpression of Bmi-1 oncoprotein correlates with axillary lymph node metastases in invasive ductal breast cancer," Breast, vol. 13, no. 5, pp. 383-388, 2004.

[48] J. Silva, V. Garcia, J. M. Garcia et al., "Circulating Bmi-1 mRNA as a possible prognostic factor for advanced breast cancer patients," Breast Cancer Research, vol. 9, no. 4, p. R55, 2007.

[49] M. J. Hoenerhoff, I. Chu, D. Barkan et al., "BMI1 cooperates with H-RAS to induce an aggressive breast cancer phenotype with brain metastases," Oncogene, vol. 28, no. 34, pp. 30223032, 2009.

[50] D. Mihic-Probst, A. Kuster, S. Kilgus et al., "Consistent expression of the stem cell renewal factor BMI-1 in primary and metastatic melanoma," International Journal of Cancer, vol. 121, no. 8, pp. 1764-1770, 2007.

[51] J.-H. Liu, L.-B. Song, X. Zhang et al., "Bmi-1 expression predicts prognosis for patients with gastric carcinoma," Journal of Surgical Oncology, vol. 97, no. 3, pp. 267-272, 2008.

[52] J. Yang, L. Chai, C. Gao et al., "SALL4 is a key regulator of survival and apoptosis in human leukemic cells," Blood, vol. 112, no. 3, pp. 805-813, 2008.

[53] J. Yang, L. Chai, F. Liu et al., "Bmi-1 is a target gene for SALL4 in hematopoietic and leukemic cells," Proceedings of the National Academy of Sciences of the United States of America, vol. 104, no. 25, pp. 10494-10499, 2007.

[54] Y. Shimono, M. Zabala, R. W. Cho et al., "Downregulation of miRNA-200c links breast cancer stem cells with normal stem cells," Cell, vol. 138, no. 3, pp. 592-603, 2009.

[55] R. Bhattacharya, M. Nicoloso, R. Arvizo et al., "MiR-15a and MiR-16 control Bmi-1 expression in ovarian cancer," Cancer Research, vol. 69, no. 23, pp. 9090-9095, 2009. 


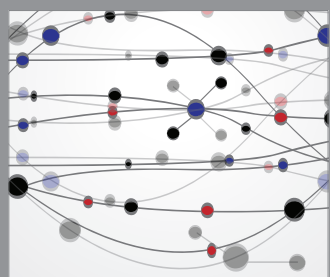

The Scientific World Journal
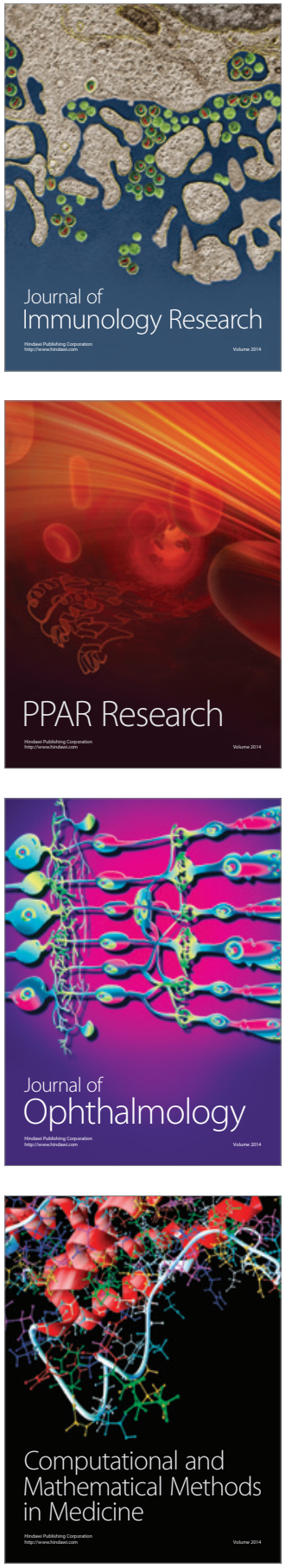

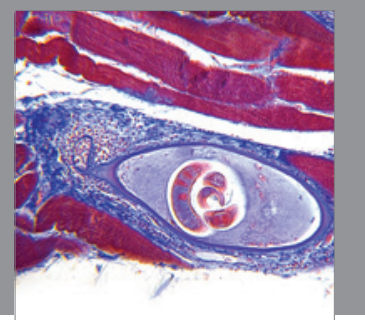

Gastroenterology

Research and Practice
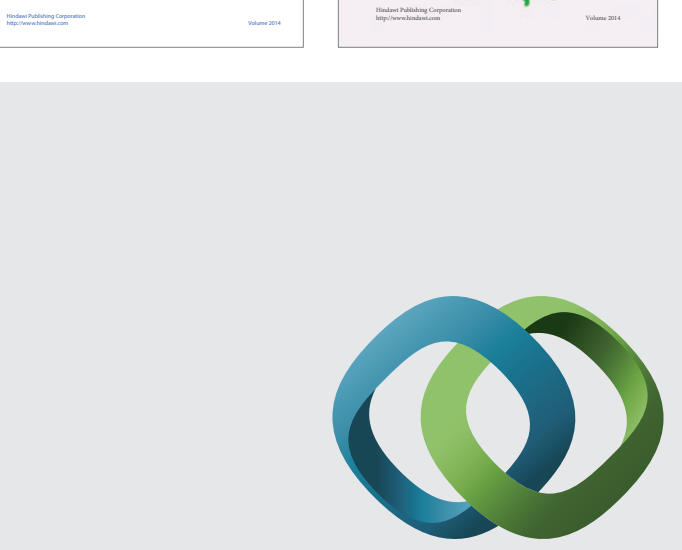

\section{Hindawi}

Submit your manuscripts at

http://www.hindawi.com
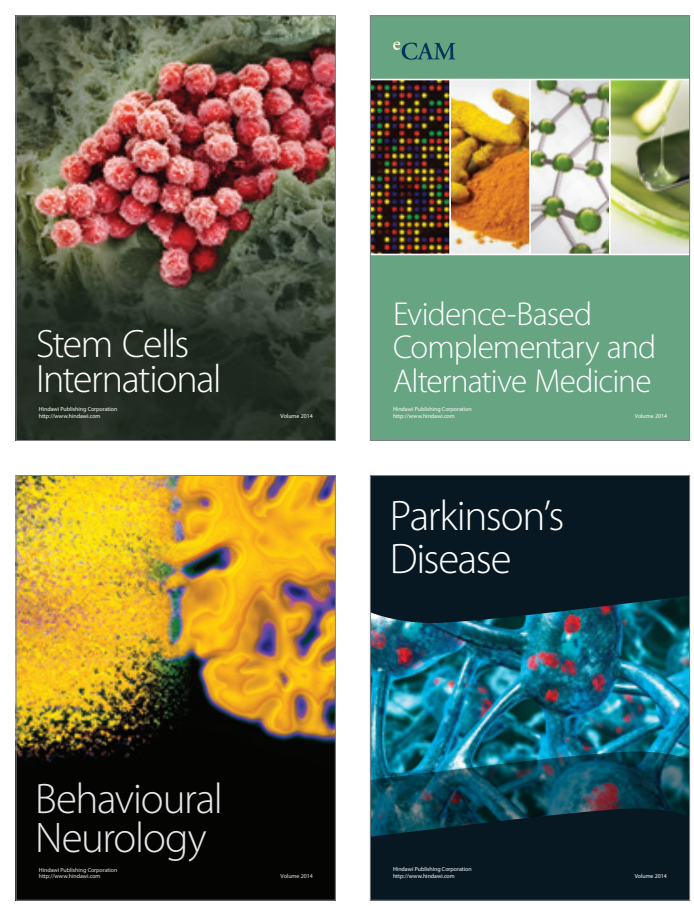

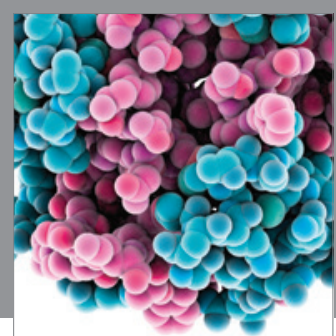

Journal of
Diabetes Research

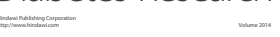

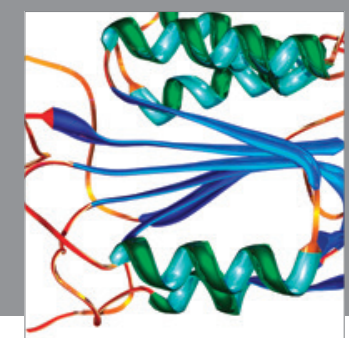

Disease Markers
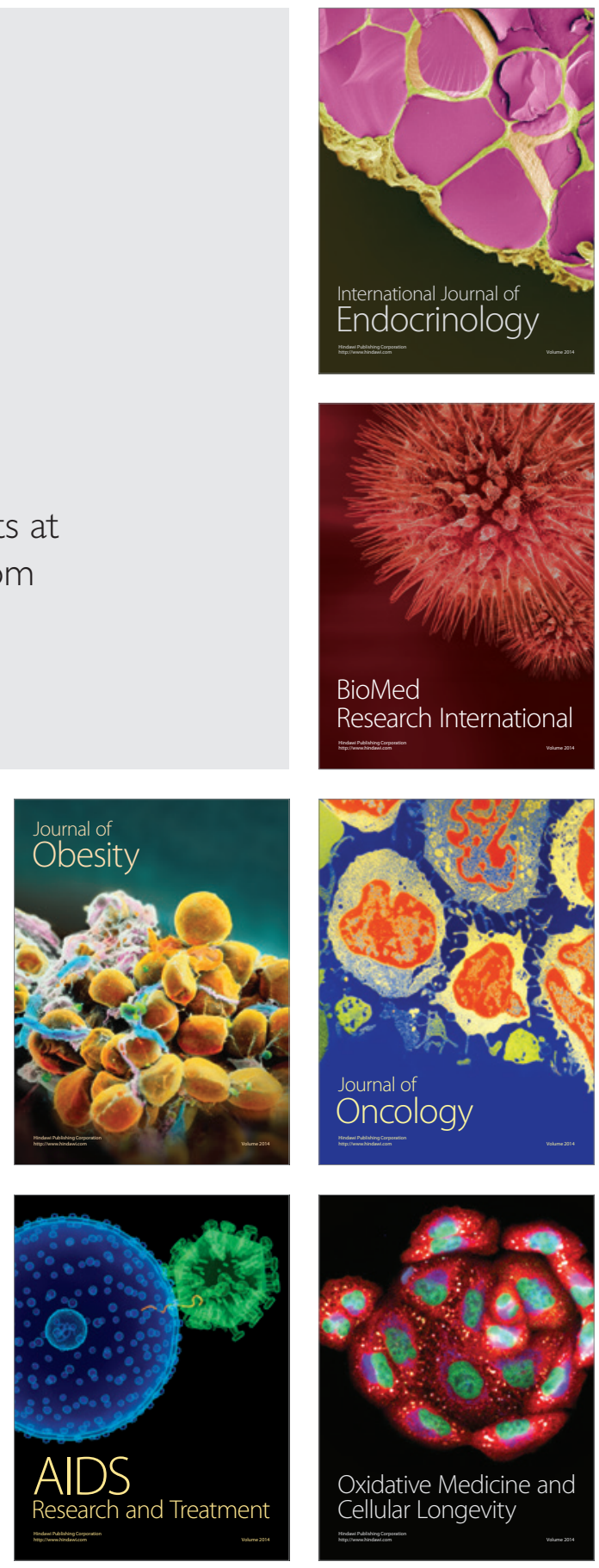